IZA DP No. 9922

Community-Based Health Insurance and Out-of-Pocket Healthcare Spending in Africa: Evidence from Rwanda

Andinet Woldemichael

Daniel Zerfu Gurara

Abebe Shimeles

April 2016 


\title{
Community-Based Health Insurance and Out-of-Pocket Healthcare Spending in Africa: Evidence from Rwanda
}

\author{
Andinet Woldemichael \\ African Development Bank \\ Daniel Zerfu Gurara \\ International Monetary Fund \\ Abebe Shimeles \\ African Development Bank \\ and IZA \\ Discussion Paper No. 9922 \\ April 2016 \\ IZA \\ P.O. Box 7240 \\ 53072 Bonn \\ Germany \\ Phone: +49-228-3894-0 \\ Fax: +49-228-3894-180 \\ E-mail: iza@iza.org
}

\begin{abstract}
Any opinions expressed here are those of the author(s) and not those of IZA. Research published in this series may include views on policy, but the institute itself takes no institutional policy positions. The IZA research network is committed to the IZA Guiding Principles of Research Integrity.

The Institute for the Study of Labor (IZA) in Bonn is a local and virtual international research center and a place of communication between science, politics and business. IZA is an independent nonprofit organization supported by Deutsche Post Foundation. The center is associated with the University of Bonn and offers a stimulating research environment through its international network, workshops and conferences, data service, project support, research visits and doctoral program. IZA engages in (i) original and internationally competitive research in all fields of labor economics, (ii) development of policy concepts, and (iii) dissemination of research results and concepts to the interested public.
\end{abstract}

IZA Discussion Papers often represent preliminary work and are circulated to encourage discussion. Citation of such a paper should account for its provisional character. A revised version may be available directly from the author. 
IZA Discussion Paper No. 9922

April 2016

\section{ABSTRACT}

\section{Community-Based Health Insurance and Out-of-Pocket Healthcare Spending in Africa: Evidence from Rwanda}

In the absence of third party and prepayment systems such as health insurance and taxbased healthcare financing, households in many low-income countries are exposed to the financial risks of paying large medical bills from out-of-pocket. In recent years, community based health insurance schemes have become popular alternatives to fill such void in the healthcare financing systems. This paper investigates the impact of these schemes on out-ofpocket spending based on three rounds of nationally representative data from Rwanda. We estimate an Extended Two-Part Model to address endogeniety in insurance enrollment and censoring in healthcare expenditure data. We find that community based health insurance program has non-linear and mixed impacts on out-of-pocket expenditure. While the program significantly increases the probability of overall spending, it decreases the amount of per capita spending on healthcare. The program also significantly reduces spending on drug but increases outpatient spending with no detectable impact on inpatient services. Furthermore, we find notable heterogeneity in treatment effects in which households in the top income distribution realize the highest reduction in out-of-pocket spending.

JEL Classification: C21, C34, D04, I13, I15

Keywords: impact, health insurance, out-of-pocket, low-income, endogeneity

Corresponding author:

Abebe Shimeles

African Development Bank Group

Immeuble du CCIA

Avenue Jean-Paul II

01 BP 1387 Abidjan 01

Côte d'Ivoire

E-mail: a.shimeles@afdb.org 


\section{Introduction}

Adverse health shocks are frequent events in low-income countries posing one of the biggest threats to the lives and livelihoods of the poor. In addition to physical suffering from illnesses, households face significant financial risk of paying large medical bills from out-of-pocket. In these countries, third party payers and prepayment systems such as health insurance and taxbased schemes are not widely available to protect households from health-related financial risks. The usual coping mechanisms to deal with large out-of-pocket medical bills are through intertemporal transfers (saving, borrowing, or selling assets), reducing current consumption levels, or forgoing medical care all together because they cannot afford it (O’Donnell et al., 2008). Each of these coping mechanisms however has detrimental impact on welfare, and in many cases catastrophic, driving them into poverty (Wagstaff et al., 2011; Leive and $\mathrm{Xu}, 2008$ ). This is particularly imperative for African countries where $50 \%$ of total healthcare expenditure is from out-of-pocket and 30\% of households cope through borrowing and selling assets (Leive and $\mathrm{Xu}$, 2008).

Community Based Health Insurance (CBHI) schemes are considered formidable alternatives to fill the void in the healthcare financing system of many low - and middle - income countries. The overarching goals of these programs are increasing access to healthcare services, protecting households from health-related financial risks, and ultimately improving health status of the poor. In recent years, governments and development partners are playing key roles in rolling out CBHI schemes at the national level, integrating them into the existing healthcare provision and financing systems, and allocating significant resources in the form of subsidies and steering operational activities. The proliferation of CBHI schemes in many low-income countries as mainstream healthcare financing mechanisms has triggered considerable analytical and policy questions concerning their impact in providing access to healthcare services and protecting households from financial risks due to illnesses.

Rwanda is one of few African countries to implement the CBHI program as integral part of its national healthcare financing system. The country started to implement the program, locally referred to as Mutuelle de santé, in 2004 and covered about 86\% of the population in 2008 (MoH, 2010). All other things being equal, health insurance is expected to change the price of healthcare services, which could in turn increases utilization more (moral hazard). Although studies find that the program has significantly increased outpatient utilization rates, there are 
some concerns that the subsidized flat premium rate of about 2 USD per person is too high for the poor, especially for families of larger sizes (Shimeles, 2010; Lu et al., 2012; Woldemichael and Shimeles, 2015). With additional expenses on transportation and nonessential drugs not covered by the insurance scheme, there is a debate that the insurance scheme could actually increase out-of-pocket cost, especially for the poor.

This paper investigates the causal effects of CBHI program on out-of-pocket healthcare spending in Rwanda. We use three rounds of nationally representative data from the Rwandan Integrated Household Living Conditions Survey conducted in 2000, 2005, and 2010. We guide our empirical analysis using a simple model of demand for health and health insurance. The major empirical issues we encounter in estimating the effect of CBHI on out-of-pocket spending are non-normal expenditure distribution and endogeneity in CBHI enrollment. Non-normality arises mainly due to high proportion of zeros and heteroskedasticity in healthcare expenditure. We observe zeros in healthcare expenditure either due to "corner solutions" in the choice problem or modern "health care goods and services” are not in individuals' choice set. Either way, high proportion of zeros poses discontinuity in the distribution of expenditure and need to be addressed (Trivedi, 2002). The second problem is endogeneity which arises due to self-selection into or out of CBHI schemes in which enrolled and uninsured individuals may exhibit behavioral differences which are also correlated with spending behavior (such as underlying health conditions, health behavior, risk aversion, etc.).

We address these important empirical issues using Extended Two-Part Model (ETPM) proposed by Deb et al. (2006). In the model, the decision to enroll in CBHI schemes, the decision to spend, and the conditional amount of spending are simultaneously modeled in a three-equation system. In addition, estimates from the Two-Part Models (TPM) in general and the ETPM in particular provide useful economic interpretation in which the first part is the probability of an "interior solution" to the choice problem and the second part is the level of consumption conditional on an “interior solution” (Trivedi, 2002). The model is estimated using Bayesian methods with Markov Chain Monte Carlo (MCMC) simulation techniques.

The evidence on the impact of SHI and CBHI schemes on out-of-pocket healthcare spending are mixed and vary from country to country. For instance, while the New Cooperative Medical Scheme (NCMS) in China have no impact in reducing out-of-pocket spending and even slightly increases financial risks (Wagstaff et al., 2009; Wagstaff and Lindelow, 2008), the New Rural 
Cooperative Medical Schemes (RCMS) have some success in reducing out-of-pocket and the incidence of “catastrophic” spending (Wagstaff and Yu, 2007; Yip and Hsiao, 2009). Similarly, findings from Vietnam (Wagstaff, 2007; Sepehri et al., 2006) and Mexico (Galarraga et al., 2010; King et al., 2009) are mixed but show some success in reducing the incidence of catastrophic and out-of-pocket spending. Studies from Africa such as Egypt's School Health Insurance program and Ghana’s National Health Insurance Program find evidence on the impact of SHI in reducing out-of-pocket expenses and “catastrophic” spending (Yip and Berman, 2001; Nguyen et al., 2011).

Despite the popularity of CBHI schemes, there is noticeable evidence gap with regards to the impact of CBHI schemes on out-of-pocket healthcare spending in the African context. For instance, out of the 18 studies systematically reviewed in Acharya (2012), only two are from Africa, Burkina Faso (Gnawali et al., 2009) and Ghana (Mensah et al., 2010), and their focus is primarily on healthcare utilization outcomes. Recent studies include Shimeles (2010) and Lu et al. (2013) from Rwanda which investigate the impact of CBHI schemes on utilization and the incidence of “catastrophic” spending. Similarly, Merbratie et al. (2013) and Yilma et al. (2015) investigate the impact of pilot CBHI program in Ethiopian on utilization, consumption and borrowing habits to finance out-of-pocket healthcare spending.

Comprehensive and systematic review of the literature has been done by Ekman (2004), Geidion et al. (2012), Acharya et al. (2010), and Escobar et al. (2010) and the consensus in the literature is that there is considerable heterogeneity in the impact of CBHI on various outcomes depending on country settings, program implementation, scheme design, etc. However, although the literature is voluminous, few studies actually establish "causality” from which meaningful policy recommendations can be drawn. In addition, the focus is mainly on the "incidence" of financial risks (“incidence” of out-of-pocket or "catastrophic” expenditure) ignoring the magnitude (depth) of the financial impact. Given that in recent years many African countries are implementing or planning to implement CBHI schemes at a national scale, measuring the impact of CBHI on out-of-pocket will guide policy debates and formulation.

Our paper contributes to the existing literature by examining the impact of CBHI on the "incidence" and the amount of out-of-pocket healthcare expenditure. The findings show that the effect of CBHI on out-of-pocket spending is non-linear. It increases the probability of spending by 32 percentage points reflecting increased utilization rates, but decreases the amount of total 
out-of-pocket expenditure by about 3,600 RwF (approximately 12 USD in 2000 prices and exchange rate). When it comes to spending on specific healthcare services, the results are mixed. While the scheme significantly decreases the amount of expenditure on drug, it increases the probability and the amount of spending on outpatient services highlighting higher utilization rates of consultation, medical examination, and laboratory services. However, we do not detect any impact on inpatient spending. There is also evidence of heterogeneity in treatment effects across income and wealth distributions. Contrary to the government's aim of making CBHI schemes accessible and affordable by the poor though subsidizing premiums, the impacts in terms of reducing out-of-pocket expenditure are higher for the richer households. In general, the results are robust to different model specifications and, not surprisingly, present overwhelming evidence of selection on observed and unobserved factors.

The rest of the paper is organized as follows. Section (2) describes the CBHI program in Rwanda. While Section (3) discusses the empirical framework, Section (4) describes the data. The results are discussed in Section (4) and Section (5) concludes the paper.

\section{Program description}

The Rwandan CBHI (Mutuelle) program was first introduced in 1999 as a pilot project in three districts (Byumba, Kabgayi, and Kabutari). Following the approval of the Mutuelle Health Insurance Policy by the government in 2004, the country formally implemented the program as integral part of its healthcare financing system. There have been numerous amendments and policy changes on the design, organizational structure, benefit packages, premiums schedules, co-pays, and other features of the program. The CBHI schemes are instituted as health insurance organizations based on a partnership between the community and healthcare providers (Diop et al., 2005). In line with the government's fiscal, administrative and political decentralization strategies, the schemes are managed at the district level in a decentralized manner. Each district has its own designated staff in charge of enrollment drives, collection of insurance premiums, and billing processes for services provided at the health center, management of the mutual health insurance fund ("Fonds Mutuelle de Sante"), etc. Management and operational activities are performed at the district level, which has a director and an auditor appointed by the Ministry of Health. In addition, elected community mobilization committees actively engage at village and cell levels serving for a two-year term $(\mathrm{MoH}, 2010)$. 
Participation in the Rwandan CBHI schemes is voluntary. Prior to 2007, enrollment was on a household basis where a household with up to seven family members pay premiums ranging between 2,500 to $11,000 \mathrm{RwF}$ per year and co-pays of up to $150 \mathrm{RwF}$ for services provided at health clinics and up to 50\% of the cost at hospitals (Lu et al., 2012; Diop et al., 2005). Since 2007, however, enrollment has been on individual basis with each member paying a flat rate of 1,000 RwF per year and co-pays of $200 \mathrm{RwF}$ at clinics and 10\% at hospitals. The CBHI program is highly subsidized where revenues from premium collection cover only $50 \%$ of the fund and the rest comes from designated government fund, other public insurance systems (RAMA), charitable organizations, NGOs, and development partners (Lu et al., 2012).

The benefit packages include comprehensive preventive and curative services and essential drugs provided at the health centers and some referral services at hospitals. After 2006, the national health insurance policy was amended to ensure members have access to a minimum service package (minimum package of activities (MPA)) at the health centers and complementary service package (Complementary Package of Activities (CPA)) at hospitals. While the MPA covers promotional, preventive, and curative services that could be provided at the health clinic level, the CPA includes services provided at hospitals including minor surgeries. The health centers also serve as gatekeepers to discourage moral hazard at the hospitals (Schneider and Diop, 2001).

\section{Theoretical Framework}

In order to guide our empirical analysis, in this section we present a simple theoretical framework of health investment and consumption with health insurance choices. It provides the basis for the empirical model which addresses self-selection in health insurance and heterogeneity that arises mainly from preferences, risk aversion, and other unobserved factors. The theoretical framework is based on Bolhaar et al. (2008) and other studies such as Brown and Finkelstein (2008) and Bajari et al. (2010). Suppose that individual $i$ earns income $Y_{i}$, which can be spent on consumption $c_{i}$ and medical expenses $m_{i}$ such that $Y_{i}=c_{i}+m_{i}$. The household derives utility from consumption and health $h_{i}$ :

$$
U\left(c_{i}, h_{i}\right)=u\left(c_{i}\right)^{\alpha} h_{i}^{1-\alpha},
$$

where $\alpha$ is the relative preference for health and consumption. A higher $\alpha$ corresponds to lower preference for health. Similarly, utility from health and consumption depends on the degree of 
risk aversion in that risk averse individuals have preference to avoid consumption shocks and invest in health to reduce shocks. Assume that health investment, denoted by $V_{i}$, consists of purchase of healthcare and associated services such as transportation. In the presence of health insurance options such as CBHI, households medical spending can be given by $m_{i}=r I_{i}+$ $p\left(I_{i}\right) V_{i}$, where $I_{i}$ denotes health insurance, $r$ denotes exogenously determined flat premium and $p\left(I_{i}\right)$ is the price of medical services.

Household's level of health depends not only on the volume of health investment but also existing health conditions denoted by $h_{i 0}$ and health shocks denoted by $\Delta_{i}$, i.e.,

$$
h_{i}=f\left(V_{i}, h_{i 0}, \Delta_{i}\right),
$$

where health increases with the volume of health investment $\left(f_{V}>0\right)$, decreases with increasing number of existing conditions and health shocks $\left(f_{\mu}<0\right.$ and $\left.f_{\Delta}<0\right)$. Let health shock takes the value 1 with $\lambda_{i}$ and 0 with probability $1-\lambda_{i}$. Then, household $i$ maximizes expected utility by choosing optimal levels of health insurance and volume of health investment. They choose optimal health insurance coverage before realization of shocks and choose optimal level of health investment after the realization of shocks. That is, individual $i$ makes optimal insurance choice by maximizing expected utility given by

$$
d_{i}=1\left[E\left[U\left(c_{i}, h_{i}\right) \mid I_{i}=1, h_{i 0}\right]>E\left[U\left(c_{i}, h_{i}\right) \mid I_{i}=0, h_{i 0}\right]\right]
$$

where $d_{i}=\{0,1\}$ and $1[\cdot]$ is indicator function taking the value 1 if the statement in the square bracket is true and zero, otherwise. Note that the optimal level of health insurance investment depends on the existing health conditions as well as preference parameters. Assuming constant relative risk aversion (CRRA) utility function $u\left(c_{i}\right)=\frac{c_{i}{ }^{1-\gamma}}{1-\gamma}$, households chose the optimal level of health investment by maximizing utility subject to the budget constraint and health function which gives us

$$
\frac{\partial U}{\partial V_{i}}=0: \quad \frac{c_{i}}{h_{i}}=\frac{\alpha(1-\gamma)}{(1-\alpha)} \frac{p\left(I_{i}\right)}{\frac{\partial f\left(V_{i}, h_{i 0}, \Delta_{i}\right)}{\partial V_{i}}}
$$

By substituting the expressions from the first order condition, we can obtain the optimal out-ofpocket medical expenditure which can be given by 


$$
m_{i}\left(I_{i}^{*}, \mathrm{~V}_{i}^{*} ; Y_{i}, r, \gamma, \delta, \mu, \Delta\right)=r I^{*}+p\left(I^{*}\right) V^{*}=Y-\frac{\alpha(1-\gamma)}{(1-\alpha)} \frac{p\left(I^{*}\right) f\left(V^{*}, \mu, \Delta\right)}{f_{v}\left(V^{*}, \mu, \Delta\right)}
$$

The implication of equation (5) is that out-of-pocket spending depends on income, health insurance status, price of healthcare services, the level of health, returns to health investment, optimal volume of health investment, the relative weight of health in the utility function $(1-\alpha)$, and the degree of risk aversion $(\gamma)$. It states that higher income, higher health status, higher weight on health investment $(1-\alpha)$ and lower risk preference $(\gamma)$ increases out-of-pocket healthcare spending. If the returns to health investment $\left(f_{v}\left(V^{*}, \mu, \Delta\right)=0\right)$ and the weight on health investment $(1-\alpha)$ are closer to zero, the model predicts zero out-of-pocket expenditure.

The theoretical framework also highlights self-selection in the uptake of health insurance. Factors such as existing health conditions, preference towards health, and risk aversion, which are unobserved, appear in both optimal health insurance choice and optimal out-of-pocket healthcare spending. It also points to the presence of greater heterogeneity in out-of-pocket spending due to differences in observed characteristics such as incomes and unobserved factors such as preference towards risk, the relative weight on health, etc. As described next, our empirical strategy captures key predictions of the theoretical model. We start by jointly estimating the decision to enroll in CBHI schemes and out-of-pocket healthcare spending. Consistent with the prediction of the theoretical model, compared to the uninsured, we expect to find higher utilization of healthcare services and lower out of pocket expenditure by the insured households.

\section{Empirical Framework}

This section lays out the empirical strategies to tackle three important selection bias, censoring, and identification. In order to address endogeneity and censoring, we implement the ETPM proposed by Deb et al. (2006). The standard TPM was first introduced by Cragg (1971) and popularized by the RAND health insurance experiment researchers in the 1980s to model healthcare expenditure data (Manning, Morris, and Newhouse (1981) and Manning, Duan, and Rogers (1987)). Unlike Tobit model, another commonly used method to model censored data, TPM is robust to high proportion of zeros and heteroskedasticity with positive skewedness and high kurtosis. In addition, the sequential decisions on whether to spend and on how much to spend are modeled separately. 
Endogeneity in health insurance choices arises because individuals self-select into or out of CBHI schemes due to factors related to the outcome. In the ETPM proposed by Deb et al. (2006), selection is modeled along with the hurdle and the expenditure equations. While selection on observables is handled by including confounding factors in the participation and the outcome equations, selection on unobservables is addressed by letting the error terms to be correlated. The third important issue is identification. We follow exclusion restriction to identify parameters in the system of equations. This issue is further discussed in section (4.3.) below.

\subsection{The Extended Two-Part Model}

Now, we present ETPM of endogenous CBHI enrolment and healthcare expenditure. Let $d_{i} \in$ $\{0,1\}$ indicates CBHI enrollment status, $y_{i} \in[0, \infty)$ denotes spending, $h_{i} \in\{0,1\}$ is dummy (hurdle) variable indicating positive spending (i.e., $h_{i}=1\left(y_{i}>0\right)$ ). The expected healthcare expenditure is given by

$$
E\left[y_{i} \mid x_{i}, d_{i}, \Theta\right]=\operatorname{Pr}\left(h_{i}=1 \mid x_{i}, d_{i}, \Theta\right) E\left[y_{i} \mid h_{i}=1, x_{i}, d_{i}, \Theta\right],
$$

where $\Theta$ is a vector of model parameters, $x_{i}$ denotes a vector of covariates in the outcome equations, $\operatorname{Pr}\left(h_{i}=1 \mid x_{i}, d_{i}, \Theta\right)$ is the probability of positive spending, and $E\left[y_{i} \mid h_{i}=1, x_{i}, d_{i}, \Theta\right]$ is the expected conditional amount of spending. In the ETPM, the probability of enrolling in CBHI schemes, the probability of positive spending, and the conditional amount of spending are modeled in a three-equation system, which can be written in latent variable forms as

$$
\begin{aligned}
& d_{i}^{*}=\beta^{d} w_{i}+\varepsilon_{i}^{d} \\
& h_{i}^{*}=\beta^{h} x_{i}+\gamma^{h} d_{i}+\varepsilon_{i}^{h} \\
& y_{i}^{*}=\beta^{y} x_{i}+\gamma^{y} d_{i}+\varepsilon_{i}^{y}
\end{aligned}
$$

where $d_{i}=1\left(d_{i}^{*}>0\right), h_{i}=1\left(h_{i}^{*}>0\right), y_{i}=1\left(h_{i}^{*}>0\right) \exp \left(y_{i}^{*}\right), 1(\cdot)$ is indicator operator, $\left\{d_{i}^{*}, h_{i}^{*}, y_{i}^{*}\right\}$ are the latent variables, $\left\{\gamma^{h}, \gamma^{y}\right\}$ are treatment effects parameters, $\left\{\beta^{d}, \beta^{h}, \beta^{y}\right\}$ are vectors of slope parameters to be estimated, and $\left\{\varepsilon_{i}^{d}, \varepsilon_{i}^{h}, \varepsilon_{i}^{y}\right\}$ are the error terms, and $w_{i}=\left[x_{i} z_{i}\right]$ is a vector of covariates in the selection equation, $z_{i}$ is exogenous variable excluded from $x_{i}$.

We assume that the error terms are jointly and normally distributed as $\varepsilon_{i} \sim n\left(0, \Sigma_{3 \times 3}\right)$, where $\varepsilon_{i}=$ $\left[\varepsilon_{i}^{d}, \varepsilon_{i}^{h}, \varepsilon_{i}^{y}\right]$. Because $d$ and $h$ are binary variables, we restrict the first two diagonal elements of $\Sigma$ to one. In the standard TPM, the hurdle and the expenditure equations are commonly assumed 
to be independent. Following the approach in Deb et al. (2006), we assume that, conditional on $\varepsilon_{i}^{d}$, the error terms in (7b) and (7c) are independent, which can be written as

$$
\begin{aligned}
& \varepsilon_{i}^{h}=\sigma_{d h} \varepsilon_{i}^{d}+v_{i}^{h} \\
& \varepsilon_{i}^{y}=\sigma_{d y} \varepsilon_{i}^{d}+v_{i}^{y}
\end{aligned}
$$

where $\sigma_{d h}$ and $\sigma_{d y}$ are the covariances capturing selection on unobservables, $v_{i}^{h} \sim n(0,1)$ and $v_{i}^{y} \sim n\left(0, \sigma^{2}\right)$ are independent, and $\operatorname{corr}\left(\varepsilon_{i}^{d}, v_{i}^{h}\right)=0$ and $\operatorname{corr}\left(\varepsilon_{i}^{d}, v_{i}^{y}\right)=0$. Then, the conditional distributions of the hurdle and the expenditure variables can be written as

$$
\begin{aligned}
& h_{i}^{*}=\beta^{h} x_{i}+\gamma^{h} d_{i}+\sigma_{d h} \varepsilon_{i}^{d}+v_{i}^{h} \\
& y_{i}^{*}=\beta^{y} x_{i}+\gamma^{y} d_{i}+\sigma_{d y} \varepsilon_{i}^{d}+v_{i}^{y} .
\end{aligned}
$$

In terms of the conditionals, the joint density of the observed data and the latent variables conditional on model parameters can be written as

$$
\begin{array}{r}
p\left(d_{i}, h_{i}, y_{i}, d_{i}^{*}, h_{i}^{*}, y_{i}^{*} \mid w_{i}, X_{i}, \Theta\right)=p\left(d_{i} \mid d_{i}^{*}, w_{i}, X_{i}, \Theta\right) \times p\left(d_{i}^{*} \mid w_{i}, X_{i}, \Theta\right) \\
\times p\left(h_{i} \mid h_{i}^{*}, d_{i}^{*}, w_{i}, X_{i}, \Theta\right) \times p\left(h_{i}^{*} \mid d_{i}^{*}, w_{i}, X_{i}, \Theta\right) \\
\times p\left(y_{i} \mid y_{i}^{*}, h_{i}^{*}, h_{i}, d_{i}^{*}, w_{i}, X_{i}, \Theta\right) \\
\times p\left(y_{i}^{*} \mid h_{i}^{*}, h_{i}, d_{i}^{*}, w_{i}, X_{i}, \Theta\right),(10)
\end{array}
$$

where $X_{i}=\left[x_{i} T_{i} \varepsilon_{i}^{d}\right]$. Due to data augmentation, the likelihood function is expanded and the latent variables are drawn from their conditional distributions (Tanner and Wong, 1987; Albert and Chib, 1991). The joint posterior distribution of parameters and latent variables, which is proportional to the product of the likelihood function, the posteriors of the parameters, and the priors, can be compactly written as

$$
p\left(\Theta, d_{i}^{*}, h_{i}^{*}, y_{i}^{*} \mid d_{i}, h_{i}, y_{i}, w_{i}, X_{i}\right) \propto\left[p\left(d_{i}, h_{i}, y_{i}, d_{i}^{*}, h_{i}^{*}, y_{i}^{*} \mid w_{i}, X_{i}, \Theta\right)\right] p(\Theta) p\left(\Theta_{0}\right) .
$$

The set of parameters to be estimated are $\Theta=\left\{\beta^{d}, \beta^{h}, \beta^{y}, \gamma^{h}, \gamma^{y}, \sigma_{d h}, \sigma_{d y}, \sigma_{y}^{2}\right\}$.

The next step is to specify the priors. We choose priors similar to those specified in Deb et al. (2006). In particular, we specify non-informative conjugate normal distributions for all slope parameters with mean zero and variance 10 (i.e, $N\left(\mu_{0}=0, V_{0}=10 I_{K}\right)$ ), and inverse gamma 
distribution for the variance $\sigma_{y 0}^{2} \sim i g\left(\frac{v}{2},\left(\frac{c}{2}\right)^{-1}\right)$, where $v=10$ and $c=5$. The priors on the covariance parameters $\sigma_{d h}$ and $\sigma_{d y}$ are specified to be informative conjugate normal distributions, which is necessary to conduct hypothesis testing using Savage-Dickey ratio of Bayes Factor. In particular, we specify a normal distribution with mean zero and variance 0.5 (i.e., $\left.N\left(0, \frac{1}{2} I\right)\right)$. We check sensitivity of the test results with tighter priors of $N\left(0, \frac{1}{5} I\right)$ and $N\left(0, \frac{1}{8} I\right)$.

The MCMC estimation algorithm for multinomial probit selection equation can be found in Deb et al. (2006). We tailored the algorithm to fit our model of ETPM with binary selection equation, which is summarized in Box 1 and detailed in Appendix A.

\begin{tabular}{ll} 
& \multicolumn{1}{c}{ Box 1: Estimation Algorithm } \\
\hline Step 1: & draw the latent variable $d_{i}^{*}$ from its conditional truncated normal distribution \\
Step 2: & draw the latent variable $h_{i}^{*}$ from its conditional truncated normal distribution \\
Step 3: & for $i=1, \ldots, n<N$ such that $h_{i}=0$, draw the latent variable $y_{i}^{*}$ from its \\
& conditional normal distribution, otherwise set $y_{i}^{*}=\ln \left(y_{i}\right)$. \\
Step 4: & draw $\beta^{d}$ for its conditional normal distribution \\
Step 5: & draw $\theta^{h}=\left[\beta^{d}, \gamma^{h}\right]$ from the joint conditional normal distribution \\
Step 6: & Draw $\sigma_{d h}$ from the conditional truncated normal distribution \\
Step 7: & draw $\theta^{y}=\left[\beta^{y}, \gamma^{y}\right]$ from the joint conditional normal distribution \\
Step 8: & Draw $\sigma_{d y}$ from the conditional normal distribution \\
Step 9: & draw $\sigma_{y}^{-2}$ from the conditional gamma distribution \\
\hline
\end{tabular}

Cycling through steps 1-9 until convergence provides the posterior parameter estimates. We wrote the estimation code in Matlab and tested on simulated data before we apply it to the real data. We conduct 10,000 MCMC simulations with the first 5,000 draws dropped as burn-ins. Convergence of the MCMC draws are assessed using trace plots as well as formal convergence diagnostic test developed by Geweke (1992). 


\subsection{Treatment Effects}

Once the post-convergence model parameters are obtained, the next step is to calculate the treatment effects. For each individual the effect of CBHI on out-of-pocket expenditure is given by

$$
T E_{i} \mid \theta=E\left[y_{i} \mid x_{i}, d_{i}=1, \theta\right]-E\left[y_{i} \mid x_{i}, d_{i}=0, \theta\right],
$$

where the conditional expected expenditure with the appropriate log retransformation is given by

$$
\begin{aligned}
E\left[y_{i} \mid x_{i}, d_{i}, \theta\right] & =\Phi\left(\beta^{h} x_{i}+\gamma^{h} d_{i}+\sigma_{d h}\left(d_{i}^{*}-\beta^{d} w_{i}\right)\right) \\
& \times \exp \left\{\beta^{y} x_{i}+\gamma^{y} d_{i}+\sigma_{d y}\left(d_{i}^{*}-\beta^{d} w_{i}\right)+\frac{1}{2} \sigma_{y}^{2}\right\} .
\end{aligned}
$$

Then, the conditional TE is integrated over the model parameters to obtain the unconditional values. This is done using Monte Carlo integration over the post-convergence vector of parameter draws $\tilde{\theta}_{R}$ as follows

$$
\widehat{T E}_{\iota}=E_{\theta}\left[T E_{i} \mid \theta\right] \approx \frac{1}{R} \sum_{r=1}^{R} T E_{i}\left(\tilde{\theta}_{r}\right)
$$

From equation (9), we can obtain the standard average treatment effects $\left(A T E=\frac{1}{N} \sum_{i=1}^{N} \widehat{T E}_{\imath}\right)$, average treatment effects on the treated $\left(A T T=\frac{\sum_{i=1}^{N} d_{i} \widehat{T E} \widehat{E}_{l}}{\sum_{i=1}^{N} d_{i}}\right)$ and the average treatment effects on the untreated $\left(A T U T=\frac{\sum_{i=1}^{N}\left(1-d_{i}\right) \widehat{T E}_{l}}{\sum_{i=1}^{N}\left(1-d_{i}\right)}\right)$.

\subsection{Test of Endogeneity in CBHI Enrollment}

There are different approaches for hypothesis testing in the Bayesian framework. The popular and simpler approach is to use Bayes factor calculated using Savage-Dickey density ratio or Gelfrand-Dey approaches. Since the standard TPM is nested in the ETPM, we use the SavageDickey density ratio approach, which is simple and appropriate for nested models (Deb et al. 2006; Li and Trivedi, 2014). We are interested to test the null hypothesis that CBHI enrollment is exogenous $\left(H_{0}: \sigma_{d h}=\sigma_{d y}=0\right)$. Then, the Savage-Dickey Bayes factor is given by

$$
B_{0,1}=\frac{p\left(\sigma_{d h}=0, \sigma_{d y}=0 \mid X, \theta\right)}{p\left(\sigma_{d h}=0, \sigma_{d y}=0\right)} .
$$


The numerator in equation (10) is the joint posterior density of $\sigma_{d h}$ and $\sigma_{d y}$ evaluated at zero, whereas the denominator is the prior density evaluated at zero. Specifically, $p\left(\sigma_{d h}=0, \sigma_{d y}=\right.$ 0 ) is calculated form a multivariate normal pdf with mean $0_{2}$ and covariance matrix $\frac{1}{2} I_{2}$ evaluated at zero. The numerator, on the other hand, is calculated from the joint conditional posterior pdf using post-convergence parameters $\tilde{\theta}_{r}$ as

$$
p\left(\sigma_{d h}=0, \sigma_{d y}=0 \mid X, \theta\right) \approx \frac{1}{r} \sum_{i=1}^{R} p\left(\sigma_{d h}=0, \sigma_{d y}=0 \mid X, \tilde{\theta}_{r}\right)
$$

The data favors the null hypothesis if the Savage-Dickey Bayes factor is greater than 1, otherwise the alternative.

\subsection{Identification through exclusion restriction}

We identify model parameters of the ETPM through cross-equation exclusion restriction. The idea is to include exogenous variable(s) which affect(s) CBHI enrollment but not correlated with out-of-pocket expenditure. Such approach is sufficient to identify model parameters and is commonly applied in the literature (Deb et al. 2006, Li and Tobias, 2011; Kean and Stavrunova, 2014; Munkin and Trivedi, 2010; Li and Trivedi, 2014).

We use membership in microfinance institutions as exclusion variable. The argument is that households who participate in microfinance activities are familiar with other community-based financial schemes such as CBHI and are more likely to participate. We argue that microfinance participation is exogenous that can be excluded from health expenditure equations. Although, there is no definite method of establishing exogeneity, we conduct overidentification tests by jointly excluding microfinance membership and cluster level CBHI membership rate to support our argument. The test results from the overid test suggest that the model is overidentified in the classical two-stage estimation.

\section{The data}

We use three rounds of nationally representative data from the Rwandan Integrated Household Living Conditions Surveys (Enquete Intégrale sur les Conditions de Vie des ménages de Rwanda (EICV)) conducted in 2000, 2005, and 2010. The EICV surveys collect information on household demographics, socio-economic characteristics, health, health insurance status, 
expenditures, incomes, wealth, etc. as well as area-level characteristics. While information on health insurance status is recorded at the individual level, expenditure on healthcare is recorded at the household level. We categorize households as "treated" if any member in the household is enrolled in CBHI schemes and "untreated”, otherwise.

Table (1) presents the proportion of households with at least one family member enrolled in different health insurance schemes. Because the CBHI program took effect in 2004, the 2000 survey provides us with pre-intervention information. The proportion of households with at least one family member enrolled in CBHI schemes were $42 \%$ and $76 \%{ }^{1}$ in 2005 and 2010, respectively. About $5 \%$ of households have at least one family member covered through employment-based health insurance (RAMA, MMI, or other private health insurance). Since we focus on comparing out-of-pocket spending among households who are enrolled in CBHI and the uninsured, our analysis excludes households with formal health insurance coverage. The final pooled sample includes 26,195 households (6,390 from 2000; 6,259 from 2005; and 13,546 from 2010 surveys).

The survey also collects household-level information on specific healthcare spending including spending on consultation visits, screening, hospital, drug, birth, and other expenses (such as durable medical equipment, health-related transportation and accommodation, etc). Expenditure information are collected in different modules and recall times depending on the frequency of purchases (one week, four weeks, and 12 months), which we aggregate to an annual per capita spending levels. Furthermore, we deflate all values to year 2000 prices using the National Institute of Statistics regional consumer price index.

Table (2) shows the simple averages of out-of-pocket spending on overall healthcare, outpatient, inpatient, and drug. The data show that per capita out-of-pocket spending on various healthcare services has considerably decreased over the years. For instance, the overall per capita spending in 2010 for the insured (uninsured) is almost half (one-fourth) of the spending in 2000. Similarly, spending on specific healthcare services has declined, which could be attributed to many factors

\footnotetext{
${ }^{1}$ Administrative records show that the national CBHI enrollment rate is 91\% in 2010 and 83\% in 2011 (MoH Annual Report, 2011). Such disparities between national level administrative reports and averages from household surveys are expected.
} 
including availability of health insurance (CBHI schemes), improved physical access to healthcare facilities at a lower cost and overall healthcare delivery system, etc.

When it comes to out-of-pocket spending by insurance status, in 2005, except on inpatient services, the uninsured spend higher amount than the insured. The converse is true in 2010, where CBHI member households spend higher amount on overall, outpatient, and inpatient services but lower amount on drug. One of the issues in these averages is that there is high proportion of zeros in the data, which is problematic if the proportion systematically differs by insurance status or other characteristics. Figure (1) shows the distribution of overall, outpatient, inpatient, and drug spending by insurance status where there is high proportion of zeros, which also vary by CBHI status. This issue is addressed in our ETPM framework.

Summary of control variables included in the analysis is presented in Table (3), which includes household demographic characteristics, number of individuals with illnesses, consumption and wealth quintiles, occupation, education, and location of residence. While consumption quartiles are constructed from per capita annual consumption expenditure for each survey year, wealth quartiles are constructed from a composite wealth index. The wealth index is calculated using principal component analysis on the number of agricultural equipment, livestock, household durables, dwelling characteristics, and size of land owned by the household. We include 29 district dummies to capture spatial variation in community-level factors including distance, geography, number of hospitals, number of clinics, the number of healthcare providers and other supply side factors.

\section{Results and Discussions}

\subsection{Participation and Endogeneity}

Tables (4)-(8) present posterior means and standard deviations of coefficients for overall, outpatient, inpatient and drug spending models. The estimates suggest that household-level demographic characteristics such as age, sex and marital status of the head, and household size are statistically significant factors in CBHI enrollment. While households with older and married heads are more likely to enroll their family members in CBHI schemes, households with male head, larger family size, and no education are less likely to enroll their family members. Health conditions, as measured by the number of individuals with major illnesses, also significantly affect CBHI enrollment. Similarly, income and wealth levels significantly affect households' 
enrollment decisions in that the well-to-dos are more likely to enroll their family members in CBHI schemes than households in the bottom income and wealth quartiles. From equity perspective, these results highlight that the schemes’ premium and benefit structures are somehow unfavorable for the poor. If "inclusiveness" is one of the objectives, there is little or no evidence that the Rwandan CBHI program has succeeded in providing affordable health insurance for the poor.

The results also show that area-level captured by district dummies and temporal factors using year dummies are statistically significant in CBHI enrollment decision capturing spatial and temporal variations at the district and national levels. In particular, compared to year 2000, households in year 2010 are more likely to be enrolled in CBHI schemes. Similarly, most district dummies are statistically significant highlighting differences in enrollment decisions depending on area of residence. Furthermore, membership in microfinance institutions is statistically significant in all models.

As shown in Tables (4)-(8), the "Hurdle" and the "Expenditure" columns, most of the control variables are "confounding” factors, significantly affecting both CBHI enrollment and the outcome variables. For instance, households with large number of sick individuals are less likely to enroll in CBHI but are more likely to spend and spend higher amount conditional on spending. Similarly, households with higher incomes are more likely to enroll in CBHI schemes and spend more on healthcare from out-of-pocket. Household in the top three income quartiles are, for instance, more likely to enroll their family members in CBHI schemes, spend positive amount, and spend higher amount conditional on positive spending. These results substantiate the importance of selection on observable factors where individuals self-select into or out of CBHI based on their demographic, socio-economic, geographic, and other characteristics.

In addition to observed factors, unobserved factors such as preference towards insurance, underlying health conditions, risk aversion, etc, play significant role in both CBHI enrollment and out-of-pocket spending behavior. If these factors are not accounted in our empirical model, the estimated treatment effects could be biased. The ETPM accounts for such bias arising from endogeneity or selection on unobserved factors. We formally test the null hypothesis of no endogeneity $\left(H_{0}: \sigma_{d h}=\sigma_{d y}=0\right)$ using the Savage-Dickey Bayes Factor. For $v_{0}=\frac{1}{2}$, the data strongly reject the null for overall, outpatient, and drug spending models. The test is consistent 
for less informative prior selections $\left(v_{0}=2 ; v_{0}=1\right)$ and more informative selections $\left(v_{0}=\right.$ $\frac{1}{2} ; v_{0}=\frac{1}{5}$; and $v_{0}=\frac{1}{8}$ ), which gives Savage-Dickey ratios of zero or very close to zero.

However, the data could not reject the null for inpatient spending model, which gives a SavageDickey ratio of 22.2. This implies that in the inpatient spending model CBHI membership can be considered as exogenous. In general, the test results underscore that if selection bias is ignored, the estimated treatment effects would be significantly biased.

\subsection{Treatment Effects}

Table (9) presents the ATEs on the probability and the amount of spending. For comparison, we also report treatment effects from the standard TPM under the assumption of random (exogenous) CBHI enrollment. The differences between the results from these two models show that the magnitude and the direction of selection bias when endogeneity is ignored.

For the most part, CBHI has a non-linear effect increasing the probability but decreasing the amount of spending. The results from the ETPM show that the ATE on the probability of spending on overall healthcare services is 31.6 percentage points whereas the ATE on the amount of spending is $-3,609 \mathrm{RwF}$. On the other hand, the scheme increases the probability and the amount of spending on outpatient services by 34.5 percentage points and $346 \mathrm{RwF}$, respectively. Given the low “initial” healthcare utilization rates and the relatively low prices for out-patient services (consultation, screening, etc), the result suggests that the effect on utilization (moral hazard) outweighs the "price effect”.

The program also reduces the amount of annual per capita spending on drug by 3,553 RwF, which is about $85 \%$ reduction compared to the average spending by the uninsured. This seems particularly perplexing since the program does not cover nonessential drugs obtained from establishments outside health facilities covered by the CBHI schemes. However, the insured have better access to clinics and hospitals where some of the drugs are covered by their insurance plans and are free of extra charges. In addition, given the prevalence of "self-medication”, using non-prescription drugs from neighborhood pharmacies and stores, it is not uncommon for the uninsured to spend higher amount on drug. As a result, although all drugs are not covered by CBHI schemes, it is still likely to find significant impact on drug spending. When it comes to inpatient services which is mainly hospitalization, the impact is neither economically nor statistically significant. 
Because the 2005 and the 2010 enrollment package and premium schedules differ, we estimate overall spending net of premium payments to see how the impact changes. In this case, CBHI increases the probability of spending by 28.6 percentage points but decreases the amount of spending net of premium payment by $-4,106 \mathrm{RwF}$. This shows that even if the premium schedule and benefit packages have changed over the years, the qualitatively and quantitative impacts of CBHI on out-of-pocket spending remain consistent and statistically significant.

When it comes to endogeneity, the magnitude of bias is prominent attenuating the effects toward zero. For instance, the estimated ATE on overall healthcare spending using standard TPM is positive and significant. If endogeneity is disregarded or enrollment is assumed to be exogenous, the ATE on overall spending would be biased by about 3,820 RwF. It is clear that compared to the uninsured, CBHI enrolled households spend more on overall healthcare services even in the absence of insurance. This is also shown by the high positive $(0.886($ std. dev. $=0.013))$ covariance between $\mathrm{CBHI}$ and the amount of expenditure, which implies that households who are likely to sign up for CBHI also spend higher amount on healthcare and vice-versa. Had we ignored this, we would end up underestimating the effect of CBHI on out-of-pocket healthcare expenditure.

The other important issue is heterogeneity in treatment effects. In order to shed some light on heterogeneity, we plot individual level-treatment effects for the treated, the untreated and the whole sample in Figures (2a) - (2e). It can be seen that there is considerable heterogeneity in the estimated treatment effects. The treatment effects on overall and drug spending are mainly in the negative domain but vary across households, whereas treatment effects on outpatient and inpatient spending are on both the negative and the positive domains highlighting the heterogeneous impact of CBHI. In order to assess how treatment effects vary by observed factors, we also plot their distributions by age, income and wealth percentiles (see Figures (3)(6)). In all models, there is strong indication that ATEs vary by age, income and wealth distributions. For instance, the effects of CBHI on overall spending is "u-shape" with higher reduction in out-of-pocket spending for households with heads aged between 20 and 60 . Interestingly, the ATEs increase as households' position in the income distribution increases to the top percentile favoring the rich. The reverse is true in the case of outpatient spending in which the impact of CBHI is to increase spending. Similarly, we observe some variation across age and wealth distributions but in a less dramatic way. 


\subsection{Sensitivity analysis}

Specifying informative priors on the covariance $\left(\sigma_{d h}, \sigma_{d y}\right)$ is necessary to conduct hypothesis testing using Savage-Dickey method. However, it also causes the posteriors to be pulled towards the priors, which could be propagated across model parameters and estimated treatment effects. Hence, it is important to assess the sensitivity of estimated treatment effects to our prior choices. Specifically, we estimate the model using less informative prior selections $\left(v_{0}=2\right.$ and $\left.v_{0}=1\right)$

and more informative selections ( $v_{0}=\frac{1}{5}$ and $v_{0}=\frac{1}{8}$ ). The results from this exercise are presented in Table (10). We can see that the magnitude and the direction of treatment effects remain stable regardless of prior selections. In addition, the Savage-Dickey ratios remain the same, rejecting the null for the overall out-of-pocket expenditure model. Therefore, we conclude that our results are robust to different prior selections.

However, consideration of other issues is in order. For instance, it is important to note that our results could be potentially biased due to measurement error in expenditure data which are selfreported. In particular, if measurement errors systematically vary by CBHI status (for instance, if the insured tend to over-report their spending than the uninsured), the results could be biased.

\section{Concluding Remarks}

In the absence of third party and prepayment systems such as health insurance and tax-based healthcare financing, households in many low-income countries are exposed to the financial risks of paying large medical bills from out-of-pocket. In recent years, CBHI schemes have become popular alternatives to fill such void in the healthcare financing systems. However, the existing evidence on the impact of CBHI schemes on out-of-pocket healthcare spending is limited, especially in the African context. In this paper, using nonrandomized household survey data from Rwanda, we investigate the impact of CBHI schemes on overall out-of-pocket spending and its components. We address issues of selection bias in health insurance enrollment and censoring in health expenditure using ETPM.

The results from this paper show that CBHI has significant non-linear impact on out-of-pocket spending, increasing the likelihood of spending but decreasing the conditional amount of spending. When it comes to specific components, the impacts are mixed in which the program 
significantly decreases spending on drug and but increases spending on outpatient visits. Moreover, we find no impact on inpatient spending. The results also show some degree of heterogeneity where the highest reduction in out-of-pocket spending is among households in the top income and wealth percentiles. This implies that although the program is subsidized, the benefit in terms of reduced out-of-pocket expenditure goes to households in the top income distribution.

\section{References}

Acharya, A., Vellakkal, S., Taylor, F., Masset, E., Satija, A., Burke, M., \& Ebrahim, S. (2012). The impact of health insurance schemes for the informal sector in low-and middleincome countries: a systematic review. The World Bank Research Observer, lks009.

Albert, J. and Chib S. (1991). Bayesian Analysis of Binary and Polychotomous Response Data. Technical Report, Bowling Green State University, Department of Mathematics.

Bajari, P., Hong, H. and Khwaja, A., 2006. ”Moral Hazard, Adverse Selection and Health Expenditures: A Semiparametric Analysis”. NBER Working Paper 12445.

Bolhaar, J., Lindeboom, M., \& van der Klaauw, B. (2012). A dynamic analysis of the demand for health insurance and health care. European Economic Review,56(4), 669-690.

Brown, J.R. and Finkelstein, A., 2008. ”The Interaction of Public and Private Insurance: Medicaid and the Long-Term Care Insurance Market”. American Economic Review 98, p.1083-1102.

Cragg, J. G. (1971). Some statistical models for limited dependent variables with application to the demand for durable goods. Econometrica: Journal of the Econometric Society, 829844

De Weerdt, J. and S. Dercon (2006). Risk-sharing networks and insurance against illness. Journal of Development Economics 81(2), 337-356.

Deb, P., Munkin, M. K., \& Trivedi, P. K. (2006). Bayesian analysis of the two-part model with endogeneity: application to health care expenditure. Journal of Applied Econometrics, 21(7), 1081-1099. 
Dercon, S. and P. Krishnan (2000). In sickness and in health: Risk sharing within households in rural Ethiopia. Journal of Political Economy 108(4), 688-727.

Diop, P., Butera, \& Damascene, J. (2005). Community-Based Health Insurance in Rwanda. World Bank, Washington, DC. (C) World Bank. https://openknowledge.worldbank.org/handle/10986/9650 License: CC BY 3.0 Unported.

Ekman, B. (2004). Community-based health insurance in low-income countries: a systematic review of the evidence. Health policy and planning, 19(5), 249-270.

Escobar, M. L., Griffin, C. C., \& Shaw, R. P. (Eds.). (2011). The impact of health insurance in low-and middle-income countries. Brookings Institution Press.

Fafchamps, M. and S. Lund (2003). Risk-sharing networks in rural Philippines. Journal of Development Economics 71(2), 261-287.

Galárraga, O., Sosa-Rubí, S. G., Salinas-Rodríguez, A., \& Sesma-Vázquez, S. (2010). Health insurance for the poor: impact on catastrophic and out-of-pocket health expenditures in Mexico. The European Journal of Health Economics,11(5), 437-447.

Geweke, J. (1992). Evaluating the accuracy of sampling-based approaches to the calculation of posterior moments. Evaluating the accuracy of sampling-based approaches to calculating posterior moments.

Giedion, U., Andrés Alfonso, E., \& Díaz, Y. (2013). The impact of universal coverage schemes in the developing world: a review of the existing evidence. Universal Health Coverage Studies Series (UNICO) UNICO Studies Series No. 25.

Gnawali, D.P., S. Pokhrel, A. Sie', M. Sanon, M. De Allegri, A. Souares, H. Dong, and R. Sauerborn (2009). The effect of community-based health insurance on the utilization of modern health care services: Evidence from Burkina Faso. Health Policy 90 (2-3): 21422.

Mensah, J., J. Oppong, and C. Schmidt (2010). An evaluation of the Ghana national health insurance scheme in the context of the health MDGs. Health Economics 19 (S1): 95-106.

Jakab, M., \& Krishnan, C. (2001). Community involvement in health care financing: impact, strengths and weaknesses: a synthesis of literature. The World Bank.

Keane, M., \& Stavrunova, O. (2011). Adverse selection, moral hazard and the demand for Medigap insurance. School of Finance and Economics, University of Technology Sydney. Unpublished Manuscript. 
Keane, M., \& Stavrunova, O. (2011). Adverse selection, moral hazard and the demand for Medigap insurance. School of Finance and Economics.

Leive, A., \& Xu, K. (2008). Coping with out-of-pocket health payments: empirical evidence from 15 African countries. Bulletin of the World Health Organization,86(11), 849-856C.

Li Qian, and Trivedi Pravin K. (2014), Adverse and Advantageous Selection in The Medicare Supplemental Market: A Bayesian Analysis Of Prescription Drug Expenditure, Health Econ., doi: 10.1002/hec.3133.

Li, M. and J. L. Tobias (2008). Bayesian analysis of treatment effects in an ordered potential outcomes model. Advances in econometrics 21, 57-91.

Long, Q., Zhang, Y., Raven, J., Wu, Z., Bogg, L., Tang, S., \& Hemminki, E. (2011). Giving birth at a health-care facility in rural China: is it affordable for the poor?. Bulletin of the World Health Organization, 89(2), 144-152.

Lu C, Chin B, Lewandowski JL, Basinga P, Hirschhorn LR, et al. (2012) Towards Universal Health Coverage: An Evaluation of Rwanda Mutuelles in Its First Eight Years. PLoS ONE 7(6): e39282. doi:10.1371/journal.pone.0039282

Manning, W. G., Duan, N., \& Rogers, W. H. (1987). Monte Carlo evidence on the choice between sample selection and two-part models. Journal of econometrics, 35(1), 59-82.

Manning, W. G., Morris, C. N., Newhouse, J. P., Orr, L. L., Duan, N., Keeler, E. B., \& Phelps, C. E. (1981). A two-part model of the demand for medical care: preliminary results from the health insurance study. Health, economics, and health economics, 103-123.

Mebratie, A., Sparrow, R., Yilma, Z., Abebaw, D., Alemu, G. and Bedi, A.S. (2013). Impact of Ethiopian Pilot Community Based Health Insurance Scheme on Health Care Utilization: A Household Panel Data Analysis. The Lancet. 381: S92

MoH (2010). Rwanda National Health Insurance Policy. Republic of Rwanda, Ministry of Health, December 2010.

MoH (2011). Ministry of Health Annual Report. Republic of Rwanda, Ministry of Health. Kigali.

Munkin, M. K. and Trivedi, P. K. (2010), Disentangling incentives effects of insurance coverage from adverse selection in the case of drug expenditure: a finite mixture approach. Health Econ., 19: 1093-1108. doi: 10.1002/hec.1636 
Nguyen, H. T., Rajkotia, Y., \& Wang, H. (2011). The financial protection effect of Ghana National Health Insurance Scheme: evidence from a study in two rural districts. Int J Equity Health, 10(4), 9-10.

O'Donnell, O. A., \& Wagstaff, A. (2008). Analyzing health equity using household survey data: a guide to techniques and their implementation. World Bank Publications.

Schneider, P., \& Diop, F. (2001). Synopsis of results on the impact of community-based health insurance on financial accessibility to health care in Rwanda. World Bank, Washington, DC.

Shimeles, A. (2010). Community based health insurance schemes in Africa: The case of Rwanda. Working Papers Series No. 120, African Development Bank, Tunis, Tunisia.

Tanner, M. A. and W. H. Wong (1987). The calculation of posterior distributions by data augmentation. Journal of the American statistical Association 82 (398), 528-540.

Trivedi, P. (2002). Patterns of health care utilization in Vietnam. World Bank Policy Research Working Paper, World Bank: Washington DC.

Wagstaff, A., \& Lindelow, M. (2008). Can insurance increase financial risk?: The curious case of health insurance in China. Journal of health economics,27(4), 990-1005.

Wagstaff, A., \& Yu, S. (2007). Do health sector reforms have their intended impacts?: The World Bank's Health VIII project in Gansu province, China. Journal of health economics, 26(3), 505-535.

Wagstaff, A., Bilger, M., Sajaia, Z., \& Lokshin, M. (2011). Health equity and financial protection: streamlined analysis with ADePT software. The World Bank, 1818 H Street NW, Washington, DC.

Wagstaff, A., Lindelow, M., Jun, G., Ling, X., \& Juncheng, Q. (2009). Extending health insurance to the rural population: An impact evaluation of China's new cooperative medical scheme. Journal of health economics, 28(1), 1-19.

Woldemichael, A., \& Shimeles, A. (2015). Measuring the Impact of Micro-Health Insurance on Healthcare Utilization: A Bayesian Potential Outcomes Approach. African Development Bank Group. Working Paper Series Nº 225.

Yilma, Z., Mebratie, A., Sparrow, R., Dekker, M., Alemu, G., \& Bedi, A. S. (2015). Impact of Ethiopia's Community-Based Health Insurance on household economic welfare. The World Bank economic review. 
Yip, W., \& Hsiao, W. C. (2009). Non-evidence-based policy: how effective is China's new cooperative medical scheme in reducing medical impoverishment?. Social science \& medicine, 68(2), 201-209.

Yip, W., \& Berman, P. (2001). Targeted health insurance in a low income country and its impact on access and equity in access: Egypt's school health insurance. Health economics, 10(3), 207-220.

\section{Appendix A: Estimation algorithm of Two-Part Model with Binary Selection}

1. For $i=1, \ldots, N$, draw the latent variable $d_{i}^{*}$ from its conditional truncated normal distribution given by

$$
d_{i}^{*} \mid \cdot \sim \begin{cases}T N_{(-\infty, 0]}\left(\mu_{d}, V_{d}\right) & \text { if } d_{i}=0 \\ T N_{(0, \infty)}\left(\mu_{d}, V_{d}\right) & \text { if } d_{i}=1\end{cases}
$$

where $\mu_{d}=\beta^{d} w_{i}+V_{d}\left[\sigma_{d h}\left(h_{i}^{*}-\beta^{h} x_{i}-\gamma^{h} d_{i}\right)+\frac{\sigma_{d y}}{\sigma_{y}^{2}}\left(y_{i}^{*}-\beta^{y} x_{i}-\gamma^{y} d_{i}\right)\right]$, and $V_{d}=$ $\left(1+\sigma_{d h}^{2}+\frac{\sigma_{d y}^{2}}{\sigma_{y}^{2}}\right)^{-1}$

2. For $i=1, \ldots, N$, draw the latent variable $h_{i}^{*}$ from its conditional truncated normal distribution given by

where $\mu_{h}=\beta^{h} x_{i}+\gamma^{h} d_{i}+\sigma_{d h} \varepsilon_{i}^{d}$.

$$
h_{i}^{*} \mid \cdot \sim \begin{cases}T N_{(-\infty, 0]}\left(\mu_{h}, 1\right) & \text { if } h_{i}=0 \\ T N_{(0, \infty)}\left(\mu_{h}, 1\right) & \text { if } h_{i}=1\end{cases}
$$

3. For $i=1, \ldots, n<N$ such that $h_{i}=0$, draw the latent variable $y_{i}^{*}$ from its conditional normal distribution given by

where $\mu_{y}=\beta^{y} x_{i}+\gamma^{y} d_{i}+\sigma_{d y} \varepsilon_{i}^{d}$.

$$
y_{i}^{*} \mid \cdot \sim \begin{cases}N\left(\mu_{y}, \sigma_{y}^{2}\right) & \text { if } h_{i}=0 \\ y & \text { if } h_{i}=1\end{cases}
$$

4. Draw $\beta^{d}$ from its conditional normal distribution given by

$$
\beta^{d} \mid \cdot \sim N\left(\mu_{\beta^{d}}, V_{\beta^{d}}\right),
$$


where $\mu_{\beta^{d}}=V_{\beta^{d}}\left[V_{0} \mu_{0}+\sum_{i=1}^{N} w_{i}^{\prime}\left\{\frac{d_{i}^{*}}{\left(1+\sigma_{d h}^{2}+\frac{\sigma_{d y}^{2}}{\sigma_{y}^{2}}\right)}-\sigma_{d h}\left(h_{i}^{*}-\beta^{h} x_{i}-\gamma^{h} d_{i}\right)-\right.\right.$
$\left.\left.\frac{\sigma_{d y}}{\sigma_{y}^{2}}\left(y_{i}^{*}-\beta^{y} x_{i}-\gamma^{y} d_{i}\right)\right\}\right]$, and $V_{\beta^{d}}=\left[V_{0}+\sum_{i=1}^{N} \frac{w_{i} w_{i}^{\prime}}{\left(1+\sigma_{d h}^{2}+\frac{\sigma_{d y}^{2}}{\sigma_{y}^{2}}\right)}\right]$.

5. Draw $\theta^{h}=\left[\beta^{d}, \gamma^{h}\right]$ from the joint conditional normal distribution given by

$$
\theta^{h} \mid \cdot \sim N\left(\mu_{\theta^{h}}, V_{\theta^{h}}\right)
$$

where $\mu_{\theta^{h}}=V_{\theta^{h}}\left[\left(\begin{array}{c}V_{0} \mu_{0} \\ V_{\gamma_{0}} \mu_{\gamma_{0}}\end{array}\right)+\sum_{i=1}^{N} X_{i}^{\prime}\left(h_{i}^{*}-\sigma_{d h} \varepsilon_{i}^{d}\right)\right]$ and $V_{\theta^{h}}=\left[\begin{array}{cc}V_{0} & 0 \\ 0 & V_{\gamma_{0}}\end{array}\right]+\sum_{i=1}^{N} X_{i}^{\prime} X_{i}$.

6. Draw $\sigma_{d h}$ from the conditional truncated normal distribution

$$
\sigma_{d h} \mid . \sim T N_{[-0.9,0.9]}\left(\mu_{\sigma_{d h}}, V_{\sigma_{d h}}\right) \text {, }
$$

where $\mu_{\sigma_{d h}}=V_{\sigma_{d h}}\left(V_{\sigma_{0}} \mu_{\sigma_{0}}+\sum_{i=1}^{N} \varepsilon_{i}^{d}\left(h_{i}^{*}-\beta^{h} x_{i}-\gamma^{h} d_{i}\right)\right)$ and $V_{\sigma_{d h}}=\left[V_{\sigma_{0}}+\right.$ $\left.\sum_{i=1}^{N} \varepsilon_{i}^{d \prime} \varepsilon_{i}^{d}\right]$.

7. Draw $\theta^{y}=\left[\beta^{y}, \gamma^{y}\right]$ from the joint conditional normal distribution given by

$$
\theta^{y} \mid \cdot \sim N\left(\mu_{\theta^{y}}, V_{\theta^{y}}\right) \text {, }
$$

where $\mu_{\theta^{y}}=V_{\theta^{y}}\left[\left(\begin{array}{c}V_{0} \mu_{0} \\ V_{\gamma_{0}} \mu_{\gamma_{0}}\end{array}\right)+\sum_{i=1}^{N} X_{i}^{\prime} \sigma_{y}^{-2}\left(y_{i}^{*}-\sigma_{d y} \varepsilon_{i}^{d}\right)\right]$ and $V_{\theta^{y}}=\left[\begin{array}{cc}V_{0} & 0 \\ 0 & V_{\gamma_{0}}\end{array}\right]+$ $\sum_{i=1}^{N} X_{i}^{\prime} \sigma_{y}^{-2} X_{i}$

8. Draw $\sigma_{d y}$ from the conditional truncated normal distribution

$$
\sigma_{d y} \mid . \sim T N_{[-0.9,0.9]}\left(\mu_{\sigma_{d y}}, V_{\sigma_{d y}}\right),
$$

where $\mu_{\sigma_{d y}}=V_{\sigma_{d y}}\left(V_{\sigma_{0}} \mu_{\sigma_{0}}+\sum_{i=1}^{N} \varepsilon_{i}^{d}\left(y_{i}^{*}-\beta^{y} x_{i}-\gamma^{y} d_{i}\right)\right)$ and $V_{\sigma_{d y}}=\left[V_{\sigma_{0}}+\sum_{i=1}^{N} \frac{\varepsilon_{i}^{d \prime} \varepsilon_{i}^{d}}{\sigma_{y}^{2}}\right]$.

9. Draw $\sigma_{y}^{-2}$ from the conditional gamma distribution given by

$$
\sigma_{y}^{-2} \sim g\left(\frac{v+N}{2},\left[\frac{c}{2}+\sum_{i=1}^{N} \frac{\left(y_{i}^{*}-\beta^{y} x_{i}-\gamma^{y} d_{i}-\sigma_{d y} \varepsilon_{i}^{d}\right)^{2}}{2}\right]^{-1}\right)
$$

Cycling through steps 1-9 until convergence provides the posteriors of parameters. 


\section{Appendix B: Tables and Figures}

Table (1): Health insurance status

\begin{tabular}{lccc}
\hline \hline & $\begin{array}{c}2000 / 2001 \\
\text { (baseline) }\end{array}$ & $2005 / 2006$ & $2010 / 2011$ \\
\hline \hline CBHI & $0 \%$ & $41.9 \%$ & $75.8 \%$ \\
Other Formal Insurance (MMI, RAMA, private, etc) & n.a. & $9.1 \%$ & $5.3 \%$ \\
Uninsured & $100 \%$ & $51.0 \%$ & $22.2 \%$ \\
No. of households & 6,390 & 6,900 & 14,308 \\
\hline \hline
\end{tabular}

Table (2): Per Capita Out-of-Pocket Healthcare Spending (RwF) in 2000 Prices

\begin{tabular}{lcccccc}
\hline \hline & & 2000 & \multicolumn{2}{c}{$2005 / 2006$} & \multicolumn{2}{c}{$2010 / 2011$} \\
& Pooled & & & & \\
& Sample & Uninsured & Uninsured & CBHI & Uninsured & CBHI \\
\hline Overall & 2,612 & 4,352 & 2,665 & 1,852 & 928 & 2,233 \\
& $(14,297)$ & $(19,448)$ & $(6,882)$ & $(7,576)$ & $(4,143)$ & $(15,596)$ \\
Overall less Premium & 2,444 & 4,352 & 2,665 & 1,852 & 824 & 1,842 \\
& $(14,294)$ & $(19,448)$ & $(6,882)$ & $(7,576)$ & $(4,136)$ & $(15,575)$ \\
Outpatient & 417 & 885 & 376 & 304 & 145 & 254 \\
& $(2,717)$ & $(4,419)$ & $(1,732)$ & $(1,337)$ & $(787)$ & $(2,171)$ \\
Drug & 1,228 & 2,860 & 1,914 & 1,113 & 321 & 295 \\
& $(7,016)$ & $(12,321)$ & $(5,718)$ & $(6,479)$ & $(1,681)$ & $(2,140)$ \\
Hospital & 281 & 566 & 307 & 382 & 34 & 146 \\
& $(4,780)$ & $(8,495)$ & $(1,608)$ & $(2,554)$ & $(319)$ & $(3,227)$ \\
\hline No. of obs. & 26243 & 6420 & 3518 & 2751 & 3169 & 10385 \\
\hline \hline
\end{tabular}


Table (3): Descriptive Statistics of Control Variables

\begin{tabular}{|c|c|c|c|c|c|}
\hline & \multirow{2}{*}{$\begin{array}{l}2000 / 2001 \\
\text { Uninsured }\end{array}$} & \multicolumn{2}{|c|}{$2005 / 2006$} & \multicolumn{2}{|c|}{$2010 / 2011$} \\
\hline & & Uninsured & $\mathrm{CBHI}$ & Uninsured & $\mathrm{CBHI}$ \\
\hline \multirow[t]{2}{*}{ Head: Age } & 43.71 & 43.30 & 45.14 & 44.23 & 45.63 \\
\hline & $(15.02)$ & $(15.63)$ & $(15.09)$ & $(16.04)$ & (15.97) \\
\hline \multirow[t]{2}{*}{ Household size } & 5.02 & 4.70 & 5.31 & 4.43 & 4.83 \\
\hline & $(2.34)$ & $(2.27)$ & $(2.30)$ & $(2.08)$ & $(2.17)$ \\
\hline \multirow[t]{2}{*}{ Mean Age in the household } & 22.72 & 23.44 & 23.10 & 24.71 & 24.62 \\
\hline & $(10.44)$ & $(11.31)$ & $(10.26)$ & $(13.28)$ & (11.48) \\
\hline Head: Male & $68.5 \%$ & $69.4 \%$ & $74.4 \%$ & $69.1 \%$ & $72.2 \%$ \\
\hline Head: Married & $17.6 \%$ & $45.7 \%$ & $60.3 \%$ & $45.9 \%$ & $57.1 \%$ \\
\hline \multirow[t]{2}{*}{ No. of individuals w/ illnesses } & 1.25 & 0.99 & 0.95 & 0.84 & 0.83 \\
\hline & $(1.30)$ & (1.18) & $(1.12)$ & $(1.08)$ & $(1.04)$ \\
\hline Cons. expenditure: 1st Quartile & $25.0 \%$ & $32.0 \%$ & $19.1 \%$ & $36.2 \%$ & $23.2 \%$ \\
\hline Cons. expenditure: 2nd Quartile & $25.0 \%$ & $25.8 \%$ & $26.6 \%$ & $29.3 \%$ & $25.1 \%$ \\
\hline Cons. expenditure: 3rd Quartile & $25.0 \%$ & $23.3 \%$ & $29.4 \%$ & $23.0 \%$ & $26.6 \%$ \\
\hline Cons. expenditure: 4th Quartile & $25.0 \%$ & $18.9 \%$ & $24.9 \%$ & $11.6 \%$ & $25.1 \%$ \\
\hline Wealth index: 1st Quartile & $25.1 \%$ & $32.4 \%$ & $19.1 \%$ & $41.6 \%$ & $21.5 \%$ \\
\hline Wealth index: 2nd Quartile & $25.1 \%$ & $27.4 \%$ & $24.6 \%$ & $29.3 \%$ & $25.1 \%$ \\
\hline Wealth index: 3rd Quartile & $25.1 \%$ & $22.6 \%$ & $30.0 \%$ & $19.7 \%$ & $27.7 \%$ \\
\hline Wealth index: 4th Quartile & $24.8 \%$ & $17.7 \%$ & $26.4 \%$ & $9.4 \%$ & $25.7 \%$ \\
\hline \multirow{3}{*}{$\begin{array}{l}\text { Head's educ.: Primary } \\
\text { Head's educ.: Secondary/Vocational/Tertiary } \\
\text { Head's educ.: No education }\end{array}$} & $25.2 \%$ & $57.0 \%$ & $59.5 \%$ & $63.0 \%$ & $62.7 \%$ \\
\hline & $3.6 \%$ & $8.0 \%$ & $10.0 \%$ & $4.6 \%$ & $8.5 \%$ \\
\hline & $70.7 \%$ & $34.4 \%$ & $29.9 \%$ & $32.2 \%$ & $28.3 \%$ \\
\hline \multirow[t]{2}{*}{ No. of wage earner in the household } & 0.54 & 0.93 & 0.84 & 1.76 & 1.43 \\
\hline & $(0.88)$ & $(1.02)$ & $(1.03)$ & $(1.45)$ & $(1.41)$ \\
\hline Urban & $22.9 \%$ & $24.5 \%$ & $14.7 \%$ & $12.3 \%$ & $13.6 \%$ \\
\hline No. of households & 6,390 & 6,259 & & 13,546 & \\
\hline
\end{tabular}


Table (4): Overall healthcare expenditure: ETPM posterior means and standard deviations

\begin{tabular}{|c|c|c|c|c|c|c|}
\hline & \multicolumn{2}{|c|}{$\mathrm{CBHI}$} & \multicolumn{2}{|c|}{ Hurdle } & \multicolumn{2}{|c|}{ Expenditure } \\
\hline & Mean & Std.Dev. & Mean & Std.Dev. & Mean & Std.Dev. \\
\hline Intercept & -1.633 & $(0.096)$ & -0.681 & $(0.080)$ & 7.049 & $(0.100)$ \\
\hline $\mathrm{CBHI}$ & & & 1.262 & $(0.084)$ & -1.659 & $(0.035)$ \\
\hline Head: Age & 0.006 & $(0.001)$ & -0.008 & $(0.001)$ & 0.004 & $(0.001)$ \\
\hline Head: Male & -0.348 & $(0.036)$ & 0.114 & $(0.028)$ & -0.122 & $(0.037)$ \\
\hline Head: Married & 0.565 & $(0.032)$ & -0.004 & (0.029) & 0.215 & $(0.033)$ \\
\hline HH: Size & -0.016 & $(0.007)$ & 0.016 & $(0.005)$ & -0.186 & $(0.006)$ \\
\hline HH: \#of individuals w/ illness & -0.056 & $(0.012)$ & 0.359 & $(0.012)$ & 0.285 & $(0.011)$ \\
\hline Head educ.: Primary & 0.312 & $(0.027)$ & 0.005 & $(0.024)$ & 0.195 & $(0.028)$ \\
\hline Head edu.: Sec/Voc/Univ & 0.510 & $(0.054)$ & 0.031 & $(0.052)$ & 0.417 & $(0.051)$ \\
\hline \# of wage earners & -0.003 & $(0.008)$ & 0.000 & $(0.009)$ & & \\
\hline $2^{\text {nd }}$ Cons. Quartile & 0.112 & $(0.034)$ & 0.260 & $(0.028)$ & 0.385 & $(0.036)$ \\
\hline $3^{\text {rd }}$ Cons. Quartile & 0.179 & $(0.037)$ & 0.469 & $(0.030)$ & 0.735 & $(0.038)$ \\
\hline $4^{\text {th }}$ Cons Quartile & 0.307 & $(0.044)$ & 0.759 & $(0.036)$ & 1.436 & $(0.044)$ \\
\hline $2^{\text {nd }}$ Wealth Quartile & 0.133 & $(0.034)$ & 0.029 & $(0.028)$ & 0.072 & $(0.035)$ \\
\hline $3^{\text {rd }}$ Wealth Quartile & 0.258 & $(0.036)$ & 0.027 & $(0.030)$ & 0.123 & $(0.036)$ \\
\hline $4^{\text {th }}$ Wealth Quartile & 0.336 & (0.039) & -0.014 & $(0.033)$ & 0.271 & (0.039) \\
\hline Urban & -0.090 & $(0.046)$ & 0.197 & $(0.037)$ & 0.478 & $(0.046)$ \\
\hline Microfinance & 0.313 & $(0.023)$ & & & & \\
\hline Year 2005/06 & & & 0.395 & $(0.030)$ & -0.670 & $(0.039)$ \\
\hline Year 2010/11 & 1.459 & $(0.027)$ & 0.674 & $(0.045)$ & 0.085 & $(0.045)$ \\
\hline Covariance. $\mathrm{CBHI}$ & & & -0.281 & $(0.044)$ & 0.886 & $(0.013)$ \\
\hline Variance & & & & & 1.706 & $(0.024)$ \\
\hline District Dummies & Yes & & Yes & & Yes & \\
\hline \multicolumn{7}{|c|}{ Predicted Expenditure (2000 Prices) } \\
\hline Whole Sample & 2,312 & (41) & & & & \\
\hline Insured & 1,410 & (28) & & & & \\
\hline Uninsured & 5,019 & $(226)$ & & & & \\
\hline No. of obs. & 26,243 & & 26,243 & & 26,243 & \\
\hline
\end{tabular}


Table (5): Outpatient expenditure: ETPM posterior means and standard deviations

\begin{tabular}{|c|c|c|c|c|c|c|}
\hline & \multicolumn{2}{|c|}{$\mathrm{CBHI}$} & \multicolumn{2}{|c|}{ Hurdle } & \multicolumn{2}{|c|}{ Expenditure } \\
\hline & Mean & Std.Dev. & Mean & Std.Dev. & Mean & Std.Dev. \\
\hline Intercept & -1.636 & $(0.078)$ & -1.651 & $(0.081)$ & 8.067 & $(0.095)$ \\
\hline $\mathrm{CBHI}$ & & & 1.072 & $(0.162)$ & -0.188 & $(0.114)$ \\
\hline Head: Age & 0.005 & $(0.001)$ & -0.005 & $(0.001)$ & 0.002 & $(0.001)$ \\
\hline Head: Male & -0.335 & $(0.027)$ & 0.067 & $(0.030)$ & 0.052 & $(0.035)$ \\
\hline Head: Married & 0.570 & $(0.024)$ & -0.076 & $(0.035)$ & -0.066 & $(0.035)$ \\
\hline $\mathrm{HH}$ : Size & -0.015 & $(0.005)$ & 0.013 & $(0.005)$ & -0.191 & $(0.006)$ \\
\hline HH: \#of individuals w/ illness & -0.070 & $(0.009)$ & 0.238 & $(0.011)$ & 0.105 & $(0.010)$ \\
\hline Head educ.: Primary & 0.295 & $(0.021)$ & 0.032 & $(0.023)$ & -0.043 & $(0.027)$ \\
\hline Head edu.: Sec/Voc/Univ & 0.493 & $(0.042)$ & 0.086 & $(0.044)$ & 0.232 & $(0.046)$ \\
\hline \# of wage earner & -0.009 & $(0.008)$ & 0.024 & $(0.008)$ & & \\
\hline $2^{\text {nd }}$ Cons. Quartile & 0.103 & $(0.027)$ & 0.151 & $(0.027)$ & 0.163 & $(0.032)$ \\
\hline $3^{\text {rd }}$ Cons. Quartile & 0.154 & $(0.029)$ & 0.298 & $(0.029)$ & 0.300 & $(0.035)$ \\
\hline $4^{\text {th }}$ Cons Quartile & 0.281 & $(0.035)$ & 0.467 & $(0.033)$ & 0.778 & $(0.040)$ \\
\hline $2^{\text {nd }}$ Wealth Quartile & 0.147 & $(0.026)$ & 0.029 & $(0.027)$ & 0.040 & $(0.032)$ \\
\hline $3^{\text {rd }}$ Wealth Quartile & 0.268 & $(0.027)$ & 0.018 & $(0.030)$ & 0.013 & $(0.034)$ \\
\hline $4^{\text {th }}$ Wealth Quartile & 0.357 & $(0.031)$ & 0.039 & $(0.032)$ & 0.167 & $(0.038)$ \\
\hline Urban & -0.070 & $(0.037)$ & 0.149 & $(0.035)$ & 0.441 & $(0.041)$ \\
\hline Microfinance & 0.386 & $(0.023)$ & & & & \\
\hline Year 2005/06 & & & 1.001 & $(0.037)$ & -2.147 & $(0.049)$ \\
\hline Year 2010/11 & 1.501 & $(0.022)$ & 0.679 & $(0.064)$ & -2.573 & $(0.064)$ \\
\hline Covaraince.CBHI & & & -0.404 & $(0.092)$ & -0.058 & $(0.063)$ \\
\hline Variance & & & & & 1.423 & $(0.019)$ \\
\hline District Dummies & Yes & & Yes & & Yes & \\
\hline \multicolumn{7}{|c|}{ Predicted Expenditure (2000 Prices) } \\
\hline Whole Sample & 385 & $(12)$ & & & & \\
\hline Insured & 689 & $(85)$ & & & & \\
\hline Uninsured & 343 & (14) & & & & \\
\hline NO. of Obs. & 26,243 & & 26,243 & & 26,243 & \\
\hline
\end{tabular}


Table (6): Inpatient expenditure: ETPM posterior means and standard deviations

\begin{tabular}{|c|c|c|c|c|c|c|}
\hline & \multicolumn{2}{|c|}{$\mathrm{CBHI}$} & \multicolumn{2}{|c|}{ Hurdle } & \multicolumn{2}{|c|}{ Expenditure } \\
\hline & Mean & Std.Dev. & Mean & Std.Dev. & Mean & Std.Dev. \\
\hline Intercept & -1.637 & $(0.071)$ & -2.488 & $(0.098)$ & 9.080 & $(0.263)$ \\
\hline $\mathrm{CBHI}$ & & & 0.334 & $(0.146)$ & -0.269 & $(0.297)$ \\
\hline Head: Age & 0.005 & $(0.001)$ & -0.005 & $(0.001)$ & 0.008 & $(0.002)$ \\
\hline Head: Male & -0.338 & $(0.027)$ & 0.030 & $(0.039)$ & 0.108 & $(0.102)$ \\
\hline Head: Married & 0.573 & $(0.023)$ & 0.027 & $(0.040)$ & -0.162 & $(0.095)$ \\
\hline $\mathrm{HH}$ : Size & -0.015 & $(0.005)$ & 0.013 & $(0.006)$ & -0.163 & $(0.015)$ \\
\hline HH: \#of individuals w/ illness & -0.065 & $(0.008)$ & 0.102 & $(0.010)$ & -0.020 & $(0.026)$ \\
\hline Head educ.: Primary & 0.295 & $(0.020)$ & 0.022 & $(0.031)$ & 0.003 & $(0.082)$ \\
\hline Head edu.: Sec/Voc/Univ & 0.492 & $(0.040)$ & -0.012 & $(0.052)$ & 0.004 & $(0.134)$ \\
\hline \# of wage earner & -0.010 & $(0.008)$ & 0.023 & $(0.010)$ & & \\
\hline $2^{\text {nd }}$ Cons. Quartile & 0.110 & $(0.025)$ & 0.170 & $(0.037)$ & 0.188 & $(0.100)$ \\
\hline $3^{\text {rd }}$ Cons. Quartile & 0.162 & $(0.028)$ & 0.293 & $(0.039)$ & 0.353 & $(0.106)$ \\
\hline $4^{\text {th }}$ Cons Quartile & 0.293 & $(0.032)$ & 0.470 & $(0.044)$ & 0.892 & $(0.117)$ \\
\hline $2^{\text {nd }}$ Wealth Quartile & 0.138 & $(0.026)$ & -0.027 & $(0.035)$ & -0.116 & $(0.087)$ \\
\hline $3^{\text {rd }}$ Wealth Quartile & 0.260 & $(0.027)$ & -0.037 & $(0.039)$ & -0.196 & $(0.093)$ \\
\hline $4^{\text {th }}$ Wealth Quartile & 0.340 & $(0.030)$ & -0.100 & $(0.044)$ & -0.004 & $(0.116)$ \\
\hline Urban & -0.067 & $(0.034)$ & 0.085 & $(0.045)$ & 0.471 & $(0.112)$ \\
\hline Microfinance & 0.379 & $(0.023)$ & & & & \\
\hline Year 2005/06 & & & 1.092 & $(0.047)$ & -2.298 & $(0.141)$ \\
\hline Year 2010/11 & 1.503 & $(0.021)$ & 0.424 & $(0.087)$ & -3.050 & $(0.187)$ \\
\hline Covariance.CBHI & & & -0.064 & $(0.084)$ & -0.010 & $(0.164)$ \\
\hline Variance & & & & & 2.158 & $(0.066)$ \\
\hline District Dummies & Yes & & Yes & & Yes & \\
\hline \multicolumn{7}{|c|}{ Predicted Expenditure (2000 Prices) } \\
\hline Whole Sample & 304 & $(27)$ & & & & \\
\hline Insured & 432 & (139) & & & & \\
\hline Uninsured & 291 & $(40)$ & & & & \\
\hline NO. of obs. & 26,243 & & 26,243 & & 26,243 & \\
\hline
\end{tabular}


Table (7): Drug expenditure: ETPM posterior means and standard deviations

\begin{tabular}{|c|c|c|c|c|c|c|}
\hline & \multicolumn{2}{|c|}{$\mathrm{CBHI}$} & \multicolumn{2}{|c|}{ Hurdle } & \multicolumn{2}{|c|}{ Expenditure } \\
\hline & Mean & Std.Dev. & Mean & Std.Dev. & Mean & Std.Dev. \\
\hline Intercept & -1.620 & $(0.080)$ & -0.470 & $(0.067)$ & 6.761 & $(0.145)$ \\
\hline $\mathrm{CBHI}$ & & & 0.031 & $(0.153)$ & -1.941 & $(0.057)$ \\
\hline Head: Age & 0.005 & $(0.001)$ & -0.007 & $(0.001)$ & 0.014 & $(0.001)$ \\
\hline Head: Male & -0.343 & $(0.028)$ & 0.080 & $(0.029)$ & -0.224 & $(0.052)$ \\
\hline Head: Married & 0.570 & $(0.026)$ & -0.045 & $(0.035)$ & 0.070 & $(0.049)$ \\
\hline HH: Size & -0.015 & $(0.006)$ & 0.016 & $(0.005)$ & -0.272 & $(0.010)$ \\
\hline HH: \#of individuals w/ illness & -0.058 & $(0.010)$ & 0.344 & $(0.010)$ & 0.391 & $(0.018)$ \\
\hline Head educ.: Primary & 0.302 & $(0.023)$ & -0.023 & $(0.026)$ & 0.231 & $(0.047)$ \\
\hline Head edu.: Sec/Voc/Univ & 0.497 & $(0.045)$ & 0.031 & $(0.045)$ & 0.479 & $(0.077)$ \\
\hline \# of wage earner & -0.012 & $(0.008)$ & -0.007 & $(0.008)$ & & \\
\hline $2^{\text {nd }}$ Cons. Quartile & 0.115 & $(0.028)$ & 0.255 & $(0.028)$ & 0.440 & $(0.069)$ \\
\hline $3^{\text {rd }}$ Cons. Quartile & 0.177 & $(0.030)$ & 0.425 & $(0.029)$ & 0.842 & $(0.069)$ \\
\hline $4^{\text {th }}$ Cons Quartile & 0.303 & $(0.038)$ & 0.654 & $(0.034)$ & 1.560 & $(0.076)$ \\
\hline $2^{\text {nd }}$ Wealth Quartile & 0.132 & $(0.028)$ & -0.055 & $(0.027)$ & -0.135 & $(0.057)$ \\
\hline $3^{\text {rd }}$ Wealth Quartile & 0.253 & $(0.030)$ & -0.143 & $(0.030)$ & -0.151 & $(0.060)$ \\
\hline $4^{\text {th }}$ Wealth Quartile & 0.333 & $(0.033)$ & -0.135 & $(0.033)$ & -0.014 & $(0.057)$ \\
\hline Urban & -0.073 & $(0.039)$ & 0.276 & $(0.033)$ & 0.347 & $(0.071)$ \\
\hline Microfinance & 0.336 & $(0.025)$ & & & & \\
\hline Year 2005/06 & & & -0.056 & $(0.028)$ & -0.050 & $(0.055)$ \\
\hline Year 2010/11 & 1.495 & $(0.023)$ & -0.700 & $(0.083)$ & 0.460 & $(0.066)$ \\
\hline Covariance.CBHI & & & -0.126 & 0.090 & 0.886 & $(0.014)$ \\
\hline Variance & & & & & 2.366 & $(0.049)$ \\
\hline District Dummies & Yes & & Yes & & Yes & \\
\hline \multicolumn{7}{|c|}{ Predicted Expenditure (2000 Prices) } \\
\hline Whole Sample & 1,855 & (64) & & & & \\
\hline Insured & 612 & (35) & & & & \\
\hline Uninsured & 4,166 & (469) & & & & \\
\hline NO. of obs. & 26,243 & & 26,243 & & 26,243 & \\
\hline
\end{tabular}


Table (8): Overall healthcare expenditure net of premium: ETPM posterior means and standard deviations

\begin{tabular}{|c|c|c|c|c|c|c|}
\hline & \multicolumn{2}{|c|}{$\mathrm{CBHI}$} & \multicolumn{2}{|c|}{ Hurdle } & \multicolumn{2}{|c|}{ Expenditure } \\
\hline & Mean & Std.Dev. & Mean & Std.Dev. & Mean & Std.Dev. \\
\hline Intercept & -1.650 & (0.089) & -0.713 & $(0.073)$ & 7.189 & $(0.116)$ \\
\hline $\mathrm{CBHI}$ & & & 0.948 & $(0.115)$ & -1.959 & $(0.034)$ \\
\hline Head: Age & 0.006 & $(0.001)$ & -0.008 & $(0.001)$ & 0.006 & $(0.001)$ \\
\hline Head: Male & -0.345 & $(0.032)$ & 0.106 & $(0.028)$ & -0.116 & $(0.041)$ \\
\hline Head: Married & 0.567 & $(0.030)$ & -0.043 & $(0.029)$ & 0.120 & $(0.038)$ \\
\hline HH: Size & -0.017 & $(0.006)$ & 0.026 & $(0.005)$ & -0.239 & $(0.007)$ \\
\hline HH: \#of individuals w/ illness & -0.059 & $(0.011)$ & 0.372 & $(0.012)$ & 0.344 & $(0.013)$ \\
\hline Head educ.: Primary & 0.306 & $(0.025)$ & 0.006 & $(0.022)$ & 0.188 & $(0.034)$ \\
\hline Head edu.: Sec/Voc/Univ & 0.508 & $(0.051)$ & 0.006 & $(0.045)$ & 0.460 & $(0.061)$ \\
\hline \# of wage earner & -0.011 & $(0.008)$ & 0.020 & $(0.008)$ & & \\
\hline $2^{\text {nd }}$ Cons. Quartile & 0.112 & $(0.031)$ & 0.211 & $(0.026)$ & 0.411 & $(0.044)$ \\
\hline $3^{\text {rd }}$ Cons. Quartile & 0.177 & $(0.034)$ & 0.379 & $(0.028)$ & 0.826 & $(0.047)$ \\
\hline $4^{\text {th }}$ Cons Quartile & 0.319 & $(0.041)$ & 0.593 & $(0.033)$ & 1.672 & $(0.053)$ \\
\hline $2^{\text {nd }}$ Wealth Quartile & 0.140 & $(0.032)$ & -0.022 & $(0.026)$ & 0.042 & $(0.043)$ \\
\hline $3^{\text {rd }}$ Wealth Quartile & 0.265 & $(0.033)$ & -0.063 & $(0.029)$ & 0.041 & $(0.043)$ \\
\hline $4^{\text {th }}$ Wealth Quartile & 0.349 & $(0.037)$ & -0.093 & $(0.032)$ & 0.238 & $(0.047)$ \\
\hline Urban & -0.081 & $(0.044)$ & 0.231 & $(0.036)$ & 0.512 & $(0.054)$ \\
\hline Microfinance & 0.324 & $(0.024)$ & & & & \\
\hline Year 2005/06 & & & 0.558 & $(0.029)$ & -0.432 & $(0.048)$ \\
\hline Year 2010/11 & 1.494 & $(0.026)$ & 0.118 & $(0.059)$ & -0.379 & $(0.052)$ \\
\hline Covariance.CBHI & & & -0.361 & $(0.064)$ & 0.894 & $(0.006)$ \\
\hline Variance & & & & & 2.463 & $(0.033)$ \\
\hline District Dummies & Yes & & Yes & & Yes & \\
\hline \multicolumn{7}{|c|}{ Predicted Expenditure (2000 Prices) } \\
\hline Whole Sample & 2,737 & $(75)$ & & & & \\
\hline Insured & 1,140 & (36) & & & & \\
\hline Uninsured & 5,246 & $(314)$ & & & & \\
\hline NO. of Obs. & 26,243 & & 26,243 & & 26,243 & \\
\hline
\end{tabular}


Table (9): Average Treatment Effects on the probability and the amount of healthcare spending (RwF: In 2000 Prices)

\begin{tabular}{lccccc}
\hline \hline & \multicolumn{2}{c}{ ETPM } & & \multicolumn{2}{c}{ TPM } \\
\cline { 2 - 3 } \cline { 5 - 6 } & Prob. & Amount & & Prob. & Amount \\
\hline \hline Overall & $0.3179^{*}$ & $-3,609^{*}$ & & $0.1963^{*}$ & $210^{*}$ \\
& $(0.019)$ & $(230)$ & & $(0.007)$ & $(71)$ \\
Spending net of premium & & & & & \\
& $0.2862^{*}$ & $-4,106^{*}$ & & $0.1028^{*}$ & $-816^{*}$ \\
& $(0.028)$ & $(320)$ & & $(0.007)$ & $(96)$ \\
Outpatient & & & & \\
& $0.345^{*}$ & $346^{*}$ & & $0.1249^{*}$ & $29^{*}$ \\
Inpatient & $(0.041)$ & $(91)$ & & $(0.007)$ & $(14)$ \\
& 0.0483 & 140 & & $0.0325^{*}$ & 49 \\
& $(0.021)$ & $(159)$ & & $(0.004)$ & $(30)$ \\
Drug & 0.0078 & $-3,553^{*}$ & & -0.051 & $-976^{*}$ \\
& $(0.043)$ & $(484)$ & & $(0.007)$ & $(99)$ \\
\hline \hline
\end{tabular}

Table (10): Sensitivity Analysis I: Sensitivity to different prior selections (2000 Prices)

\begin{tabular}{lcccc}
\hline \hline & \multicolumn{4}{c}{ Prior Selection } \\
\cline { 2 - 5 } & 2 & 1 & $1 / 5$ & $1 / 8$ \\
\hline \hline ATE on the probability of spending & 0.317 & 0.317 & 0.315 & 0.317 \\
& $(0.016)$ & $(0.017)$ & $(0.017)$ & $(0.018)$ \\
ATE on the amount of spending (RwF) & $-3,624$ & $-3,625$ & $-3,639$ & $-3,605$ \\
& $(215)$ & $(221)$ & $(222)$ & $(231)$ \\
Cov.Hurdle & & & & \\
& -0.2783 & -0.280 & -0.2734 & -0.2794 \\
Cov.Exp. & $(0.038)$ & $(0.041)$ & $(0.040)$ & $(0.044)$ \\
& 0.8863 & 0.8866 & 0.8855 & 0.8841 \\
Variance & $(0.014)$ & $(0.013)$ & $(0.014)$ & $(0.015)$ \\
& 1.707 & 1.7073 & 1.7079 & 1.7091 \\
Bayes Factor & $(0.024)$ & $(0.024)$ & $(0.026)$ & $(0.026)$ \\
\hline \hline
\end{tabular}


Figure (1): Histogram of log of out-of-pocket healthcare spending on overall, outpatient, inpatient, and drug expenditures

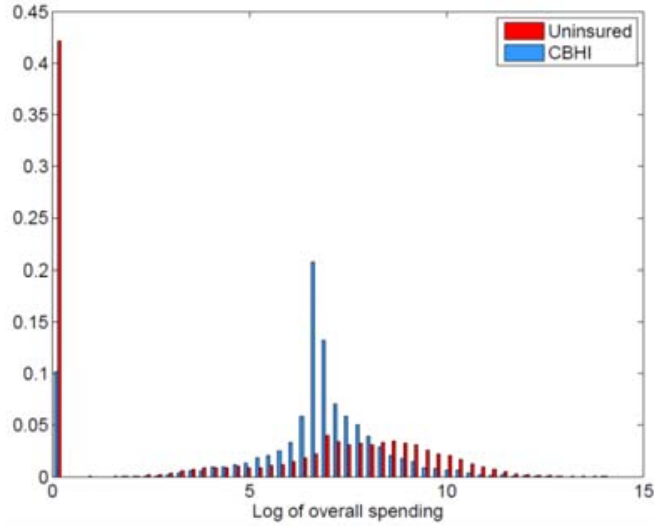

(a) Overall

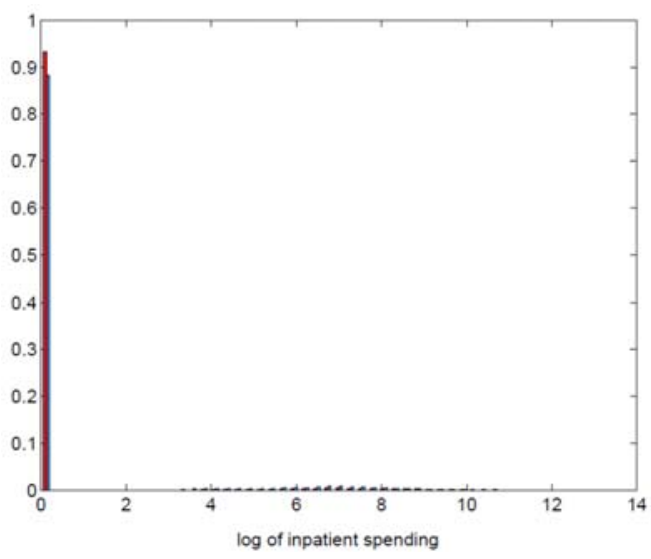

(c) Inpatient

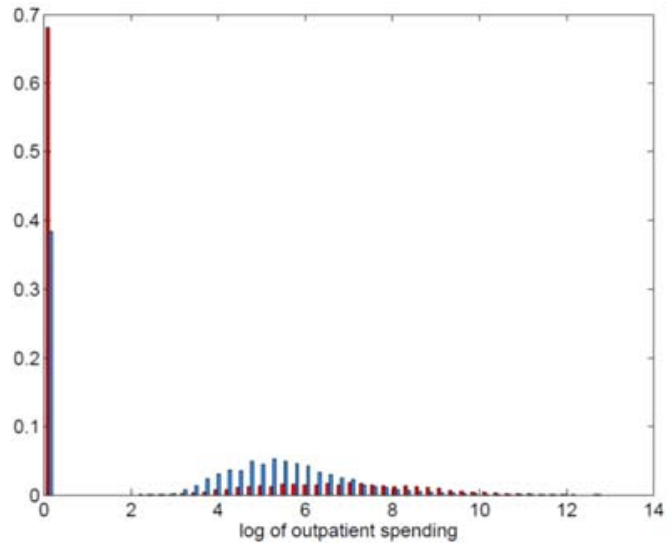

(b) Outpatient

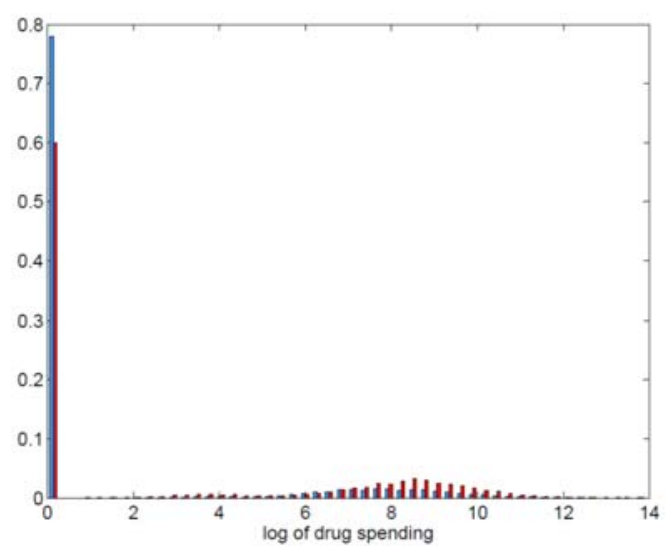

(d) Drug 
Figure (2): Kernel density of treatment effects

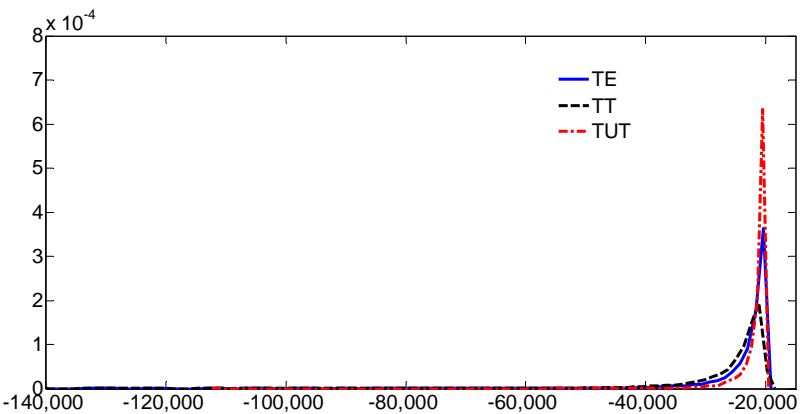

(a) Overall spending

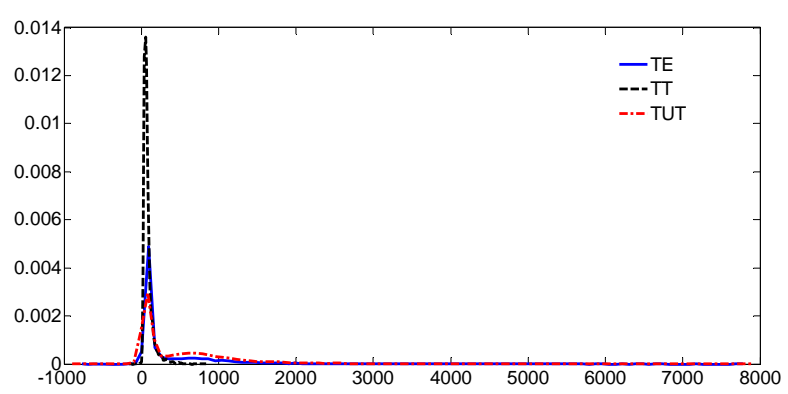

(c) Outpatient spending

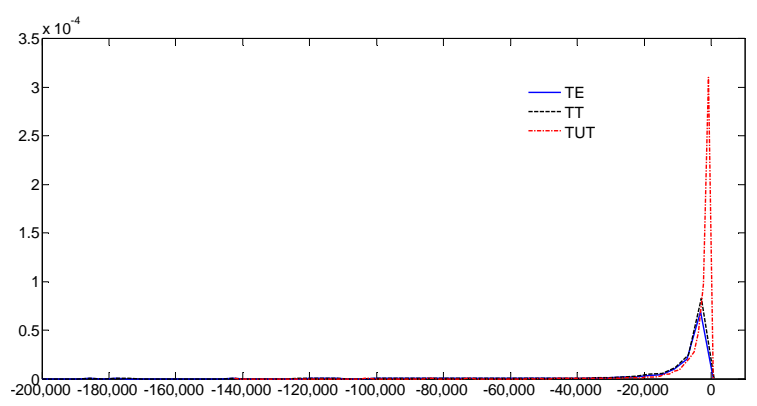

(e) Drug spending

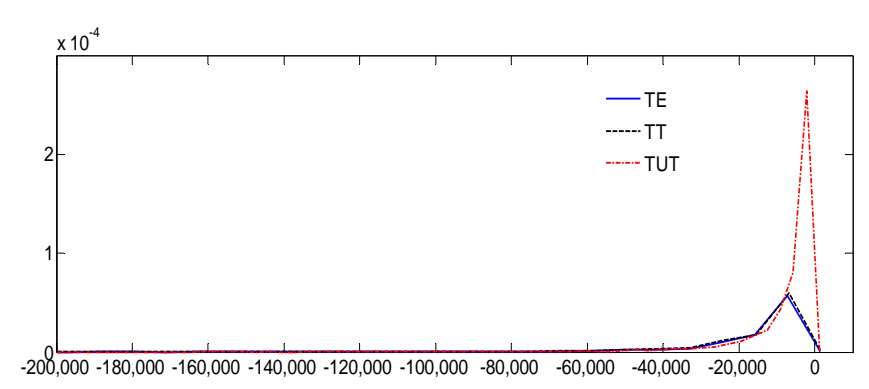

(b) Overall spending net of premium

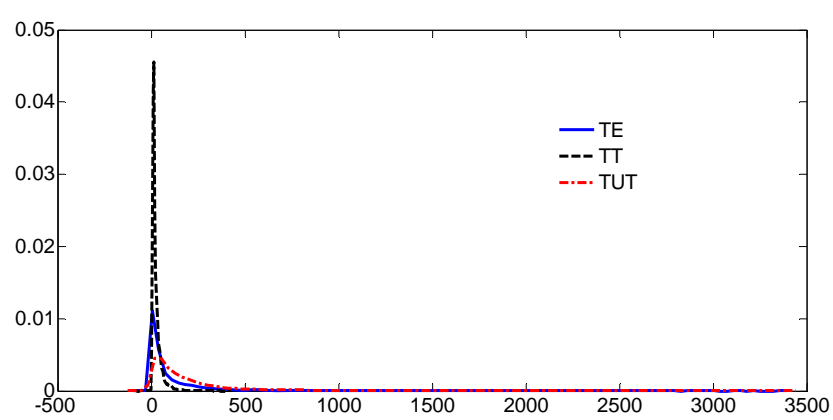

(d) Inpatient spending 
Figure (3): ATE on overall out-of-pocket expenditure by age, income, and wealth percentiles
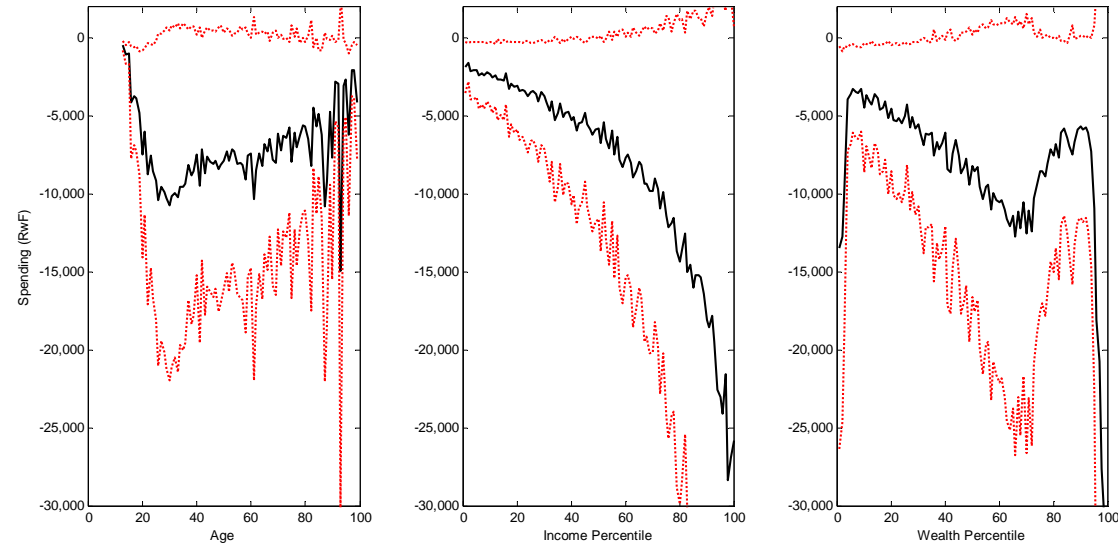

Figure (4): ATE on outpatient expenditure by age, income and wealth percentiles
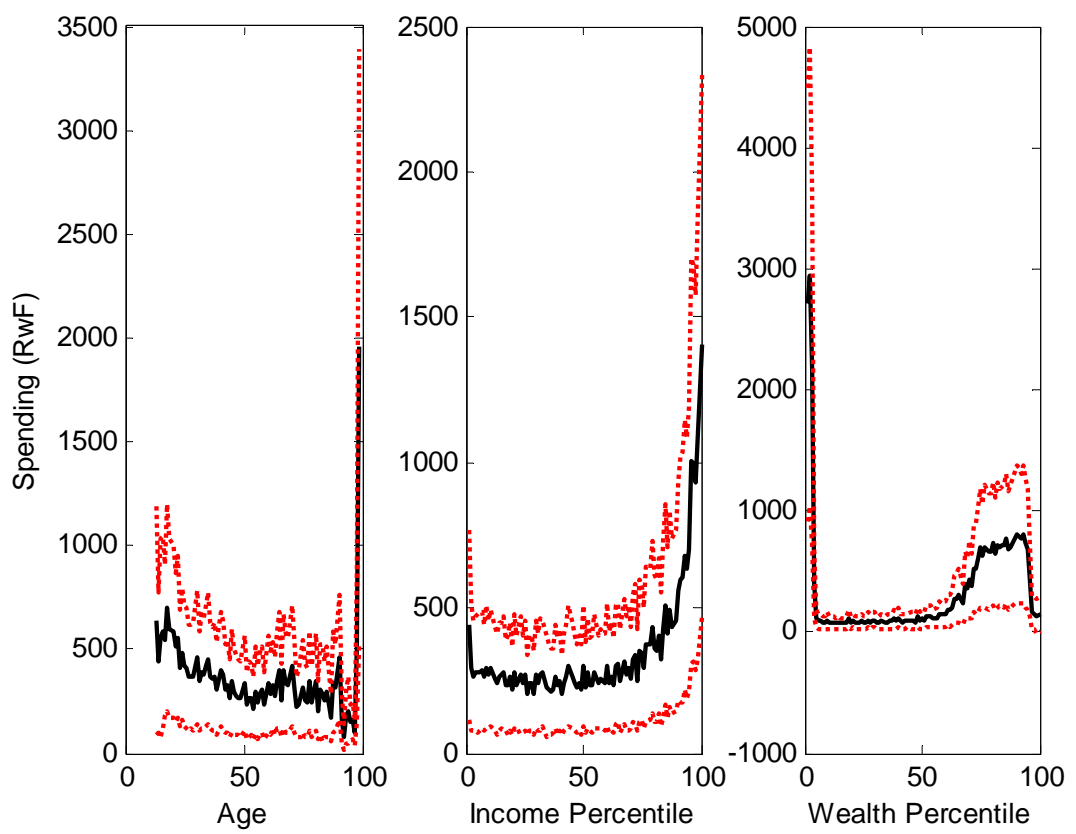
Figure (5): ATE on inpatient expenditure by age, income and wealth percentiles
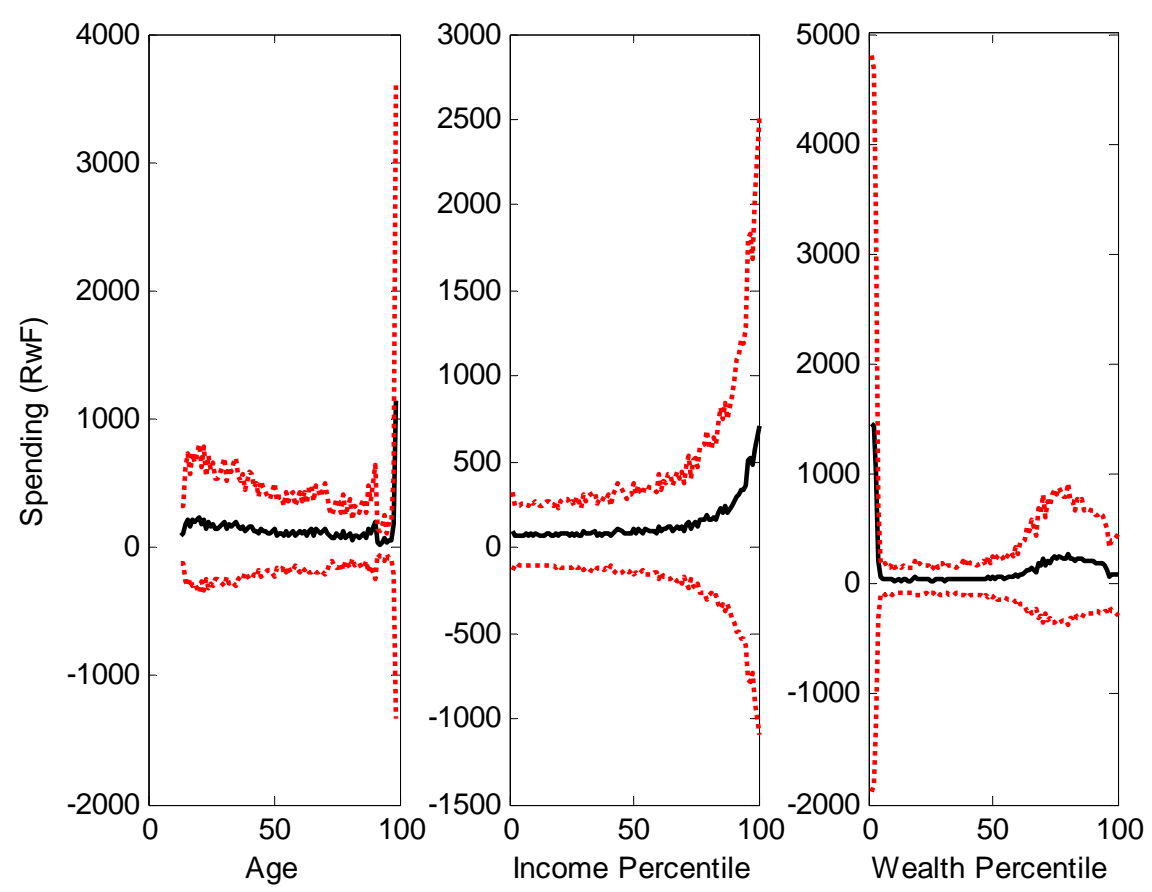

Figure (6): ATE on drug expenditure by age, income and wealth percentiles
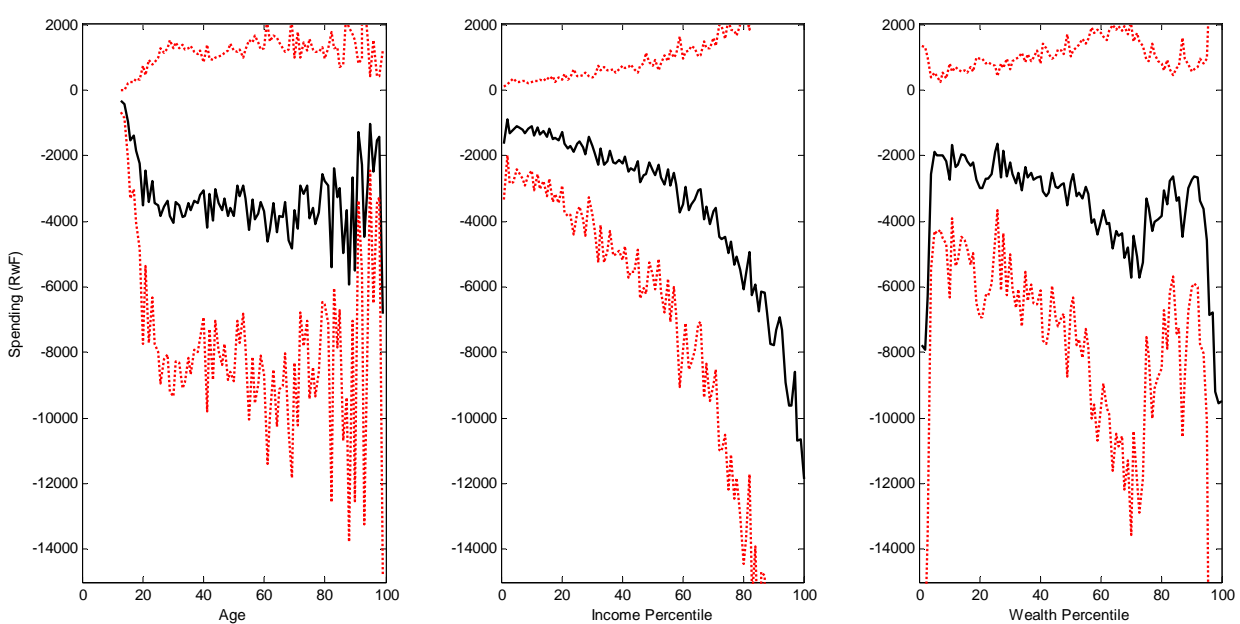